\title{
Tensioning-Phase Box Girder Deformation Prediction Model Based on Ant Colony Algorithm and Residual Correction
}

\author{
Gangnian Xu $(\mathbb{D}$, Youzhi Wang $\mathbb{D}$, Shangbin Liu $(\mathbb{D}$, and Shimin Wang \\ School of Civil Engineering, Shandong University, Jinan 250061, China \\ Correspondence should be addressed to Youzhi Wang; wangyouzhi@sdu.edu.cn
}

Received 17 August 2018; Revised 9 November 2018; Accepted 29 November 2018; Published 17 December 2018

Academic Editor: Mohammad A. Hariri-Ardebili

Copyright (C) 2018 Gangnian Xu et al. This is an open access article distributed under the Creative Commons Attribution License, which permits unrestricted use, distribution, and reproduction in any medium, provided the original work is properly cited.

\begin{abstract}
The girder of prestressed concrete continuous box girder bridge strengthened by a stay cable system has a very complex deformation mechanism, and it is difficult to establish accurate numerical model for prediction. For these problems, a prediction method based on the combination of ant colony algorithm and residual combination correction model is proposed. In this method, the measuring points are considered as the cities in TSP ant colony algorithm, the information function model and heuristic function model are constructed, the pheromone update mechanism and ant search mechanism are established, and the deformation prediction of the main girder based on ant colony algorithm prediction model is achieved. On this basis, in order to fit the random change process of main girder deflection better, the periodic function generated by harmonic transform and sine function are introduced to modify the predicted results, which makes up for the low precision defect of single model. The results show that compared with finite element method, unequal interval gray model $(1,1)$ (UIGM $(1,1)$ ), one-time residual correction UIGM $(1,1)$, Markov chain residual correction UIGM (1,1), and ant colony algorithm model, this model can reflect the space-time effect and casual fluctuation feature of the development of girder deformation better and also has higher prediction accuracy and efficiency. The mean relative error of the predictive value is $3.39 \%$, the posterior error ratio is 0.060 , and the accuracy level reaches level 1 . This model provides a new way for the girder deformation prediction of bridge strengthened by the stay cable system.
\end{abstract}

\section{Introduction}

It has become a worldwide problem that midspan lag and box girder cracks are common in prestressed concrete (PSC) continuous box girder bridges $[1,2]$. The method of strengthening with a stay cable system (SCS) can fairly well solve this kind of problems, ensures the safety of the bridge structure, and extends the service life of the bridge; this method gradually gains the attention of the engineering community [3]. However, affected by the natural environment and anthropic factors, the deformation mechanism of existing bridge is still unclear [4], which brings great difficulty to the deformation prediction of main girder strengthened by such system in tension phase. As a result, how to predict the deformation of the main girder becomes one of the key technical problems in the cable-stayed system reinforcement project.

At present, the deformation calculation methods of bridge structure mainly include theoretical analysis method, model test method, and numerical simulation method, intelligent prediction method. Among them, the theoretical analysis often adopts the idealized mechanical model, resulting in the relatively big difference between the theoretical calculation results and the measured values [5]. Although the model test can directly reflect the deformation of the main girder, it has a high cost and some limitations in the deformation prediction of existing bridges. Numerical simulation method can well simulate the variation rules of the main girder deformation; however the selection of the calculation parameters and the constitutive model has a relatively big impact on the calculation results; therefore this method needs high techniques and does not have universal applicability [6-8]. Therefore, based on the monitoring data, using intelligent forecasting model to predict the deformation of the bridge is a more practical approach; this method not only saves costs, but also improves the accuracy and speed of the calculation to a great extent.

Unequal interval grey model $(1,1)$ (UIGM $(1,1))$ is a grey dynamic prediction model consisting of a single-variable, 
first-order differential equation; it is a popular model of grey system theory and has no special requirements and limitations on experimental data, so it has a very wide application field $[9,10]$. The essence of establishing this model is making a single accumulated generating operation of raw data so that the generated data could have some regularity, and to obtain the fitting curve by establishing the differential equation model so that the system can be predicted [11]. However, UIGM $(1,1)$ can solve the change problem of single measuring point position only but not analyze the change rules of multiple positions associated with each other at the same time, so that the prediction model has the defects of low prediction efficiency, low prediction accuracy, and unstable overall performance. In practical application, numerical simulation method and UIGM $(1,1)$ output predicted values lower than the measured values, failing to achieve high prediction accuracy.

Ant colony algorithm (ACA), a new heuristic bionic algorithm put forward by Dorigo M. et al., has the capacity of solving the problems of "complexity", "nonlinearity" and "uncertainty", "high cost" and obtains good results in longterm settlement prediction of tunnel [12]. However, when solving the large-scale prediction problem, the model also has a low prediction accuracy and its residual sequence is usually alternatively positive and negative and has regularity which is not so regular. This phenomenon means the original data column often implies random components which make original sequence present the wave characteristic. In order to improve the prediction accuracy of the model, it is necessary to set up reasonable residual correction model to continue fixing it, so that the prediction accuracy could be improved.

According to the analyses above, this paper proposes a prediction method based on the combination of ant colony algorithm and residual combination correction model (ACAC model) to predict the deformation of main girder. First, ant colony algorithm is used to solve the problems of "complexity", "nonlinearity" and "uncertainty", "high cost", excavate the inherent rules of sampling data, and realize the quantitative prediction of the change in the next phase. Secondly, the periodic sequence function and sine function generated by harmonic variation are used to fit the residual sequence, which is used to modify ant colony algorithm model prediction value and compensate the deflect of low precision of the single prediction model, so that the model could achieve a higher prediction accuracy. The effect of this model was verified by the measured data of the main girder in the tensioning phase. The example analysis shows that the prediction accuracy of this model is better than that of UIGM $(1,1)$ model and ant colony algorithm model; this model has a certain theoretical and engineering application value.

\section{Ant Colony Algorithm Prediction Model}

2.1. The Basic Principle and Mathematical Model of Ant Colony Algorithm. Ant colony algorithm [13] is inspired by ants feeding behaviors; scientists found that ants have no vision, and they cannot grasp the relevant geographic information in the region, but the ant colony can find the optimal path from the nest to the food source. Study finds that ants release a kind of pheromones on the path of travel when feeding, through the pheromones, the ant colony transmit messages with each other to find the optimal path. The ants are able to perceive the presence and intensity of such substances in their foraging process and guide their movement in the direction; they tend to move in the direction toward high intensity of such substances. In addition, pheromone is a kind of volatile substance that evaporates over time. Therefore, more of the pheromones in the path which is away from the nest has been evaporated, then the ants tend to walk on shorter path, and the collective foraging behavior of ant colony shows a positive feedback phenomenon. The shorter a path is, the more ants will pass it, then the greater the intensity of the pheromones left behind is, the greater the probability that the latter will choose the path is. The ant individuals work together through this kind of pheromones and finally choose the shortest path.

Combining the Traveling Salesman Problem (TSP), this paper introduces ant colony algorithm; its mathematical model can be described as follows: to set the number of cities in the plane to be $N, B_{\mathrm{g}}(t)$ is the number of ants in city $g$ at time $t$; that is, the total number of ant colonies is

$$
m=\sum_{g=1}^{N} B_{g}(t)
$$

Suppose $\tau_{g h}^{k}(t)$ is the information function; it represents the residual pheromones concentration of ant $k$ on the city line $(g, h)$ at time $t$. Generally, it is assumed that the pheromones concentration $\tau_{\mathrm{gh}}(0)$ on each path at the initial moment is equal.

Taboo list $\operatorname{tabu}_{k}(k=1,2, \ldots, m)$ is used to record the city where the ant $k$ is passing; the collection $\operatorname{tabu}_{k}$ is constantly updated with the search process of the ant. During the traversal, the ant calculates state transition probability based on the number of pheromones and the elicitation information in each route [14]. $P_{g h}^{k}(t)$ represents the state transition probability of ant $k$ transferring from city $g$ to city $h$ at time $t$, and its expression is as follows:

$$
\begin{aligned}
& P_{g h}^{k}(t) \\
& = \begin{cases}\frac{\left[\tau_{g h}(t)\right]^{\alpha} \times\left[\eta_{g h}(t)\right]^{\beta}}{\sum_{z \in \text { allowed }_{k}}\left[\tau_{g z}(t)\right]^{\alpha} \times\left[\eta_{g z}(t)\right]^{\beta}}, & h \in \text { allowed }_{k} \\
0, & \text { otherwise }\end{cases}
\end{aligned}
$$

In the formula, $\alpha$ is the relative importance of the trajectory, $\alpha \in[0,5]$, and the larger $\alpha$ is, the more likely the ant is to choose the path that other ants have already passed; it indicates that the ants are more cooperative; $\beta$ is the relative importance of visibility, $\beta \in[0,5]$; it reflects the importance of the heuristic factor to the path selection of ant in the search process, the larger $\beta$ is, the closer the state transition probability is to the greedy rule; allowed $_{k}=\{1,2, \ldots, N\}$ $\mathrm{tabu}_{k}$ represents the collection of candidate cities that ant $k$ has not yet traveled. 
The heuristic function $\eta_{\mathrm{gh}}(\mathrm{t})$ represents the degree of expectation that the ant moves from city $g$ to city $h$, and its expression is

$$
\eta_{g h}(t)=\frac{1}{d_{g h}}
$$

In the formula, $d_{g h}$ represents the distance between city $g$ and city $h$. The smaller $d_{\text {gh }}$ is, the bigger $\eta_{\text {gh }}(\mathrm{t})$ is, the bigger $P_{g h}^{k}(t)$ is.

When the ants are traveling in the city, the pheromones are constantly updated according to formulae (4) and (5).

$$
\begin{aligned}
\tau_{g h}(t+1) & =(1-\rho) \tau_{g h}(t)+\Delta \tau_{g h}(t) \\
\Delta \tau_{g h}(t) & =\sum_{k=1}^{m} \Delta \tau_{g h}^{k}(t)
\end{aligned}
$$

In the formula, $\rho$ is the persistence coefficient, $\rho \in(0,1)$. The greater the value of $\rho$ is, the greater the chance that the path that has been traversed will be chosen again is, and it will affect the globality and randomness of the algorithm. If $\rho$ is too small, it will reduce the convergence rate of the algorithm. $\Delta \tau_{g h}^{k}$ represents the increment of pheromones left by the ant $k$ in the path $(g, h)$ during this cycle.

Three models were developed by Colorni A. et al. according to the pheromone update method, namely, Ant-Cycle model, Ant-Quantity model, and Ant-Density model [15]:

Ant-Cycle model:

$$
\Delta \tau_{g h}^{k}(t, t+n)= \begin{cases}\frac{Q}{L_{k}}, & \text { if the } k \text { th ant moves from } \\ & \text { city } g \text { to city } h \text { in this cycle } \\ 0, & \text { otherwise }\end{cases}
$$

Ant-Quantity model:

$$
\begin{aligned}
& \Delta \tau_{g h}^{k}(t, t+1) \\
& \quad= \begin{cases}\frac{Q}{d_{g h},} & \text { if the } k \text { th ant moves from city } \\
& g \text { to city } h \text { between } t \text { and } t+1 \\
0, & \text { otherwise }\end{cases}
\end{aligned}
$$

Ant-Density model:

$$
\Delta \tau_{g h}^{k}(t, t+1)= \begin{cases}Q, & \text { if the } k \text { th ant moves from } \\ & \text { city } g \text { to city } h \text { in this cycle } \\ 0, & \text { otherwise }\end{cases}
$$

where $Q$ is a constant, denoting the strength of pheromones; when its value is too large, it is easy to make the algorithm converge to the local minimum value, and if it is too small, it will slow the global convergence rate [16]; $L_{k}$ is the path length of the ant $k$.

The Ant-Cycle model uses the overall information; that is, the ant updates the pheromone on each path after a complete tour. The latter two models rely on local information; that is, the ant updates the pheromone in every step. The previous research has shown that the Ant-Cycle model outperforms the other two in dealing with the TSP $[17,18]$, because the pheromone increment in this model only depends on the path length $L_{k}$ of ant $k$ in this cycle and has nothing to do with the path length between $g$ and $h$. In addition, the ants going through the shorter path will arrive at the destination earlier and release pheromone on the way back from the original path. With a relatively high pheromone concentration, the shorter path will attract even more ants.

\subsection{Construction of Deformation Prediction Model Based on} Ant Colony Algorithm. According to the deformation curve of the main girder in three continuous tensioning phases, the deformation difference between the last two phases of a measuring point is closely related to (1) the deformation difference between the first two phases of this measuring point and (2) the result of the deformation difference between the first two phases of another measuring point minus that of yet another measuring point. This relationship is consistent with the positive feedback mechanism of the ACA; that is, the present behaviour can strengthen the future behaviour. Hence, the deformation difference between the first two phases of the main girder was analogized as the present behaviour and taken as the input parameters of the ACA prediction model. On this basis, it is possible to predict the deformation difference between the last two phases in an accurate manner.

Establishing reasonable heuristic function and information function is the key of constructing the deformation prediction model of the reinforced girder. Among them, the information function reflects the influence degree of the whole ant colony's cumulative experience on ants' path selection, and the inspiration function reflects the degree of influence of the ants' individual experience on selecting path. In order to apply the basic idea of ant colony algorithm into the deformation of the girder strengthened by a stay cable system, it is necessary to establish a similar colony path selection mechanism according to the actual deformation of the early tension phase of the main girder. In this paper, the monitoring points of the bridge are considered as the cities where the ants travel in TSP; in the course of selecting the path, the ant tends to move towards the measuring point of the larger deformation. As a result, the cumulative deformation of a site is regarded as an information function which can reflect the whole ant colony's cumulative experience. However, the difference of cumulative deformation of a certain measurement point in each period can be regarded as an inspiration function which reflects the experience of an individual ant. After calculating the transition probability based on the information function and the heuristic function of the path, ants move to the next point and release a certain concentration of pheromones on the path that they have passed in order to increase the cumulative experience of the whole ant colony. Thus, the positive feedback and autocatalytic mechanism of path selection of ant colony algorithm is accomplished. 
Based on this, the initial information function $\tau_{\text {gh }}(0)$ and the heuristic function $\eta_{\mathrm{gh}}(\mathrm{t})$ are established as follows:

$$
\begin{aligned}
& \tau_{g h}(0)=\left(\Delta W_{h}-\Delta W_{\text {min }}\right) \frac{Q}{\Delta W_{\text {sum }}} \\
& \eta_{g h}(t)=\Delta W_{h}-\Delta W_{g}
\end{aligned}
$$

In the formula, $\Delta W_{\mathrm{h}}$ and $\Delta W_{\mathrm{g}}$, respectively, represent the difference between the deformation of measure point $h$ and measure point $g$ in the two adjacent tension phases. $\Delta \mathrm{W}_{\text {min }}$ and $\Delta \mathrm{W}_{\text {sum }}$, respectively, represent the minimum value and the sum of the measure point deformation difference between two adjacent tension phases in the search space. From formula (9), we can see that the initial information function is positively correlated with the deformation difference of $h$ measuring point. In formula $(10), \eta_{\mathrm{gh}}(\mathrm{t})$ reflects the desired value that the ant moves from point $g$ to point $h$; that is, the larger the deformation difference of $h$ point compared with that of $g$ point, the easier the ant transfers $h$ point.

Unlike the TSP, the ant movement of the ACA depends on the deformation difference of measuring point between tensioning phases rather than the path length. The pheromone update method is similar to that in Ant-Quantity model; i.e., the ants update the pheromone in each step. Thus, the concentration of pheromone $\Delta \tau_{g h}^{k}(t, t+1)$ released by ant $k$ on path $(g, h)$ between time $t$ and $t+1$ can be calculated by

$$
\Delta \tau_{g h}^{k}(t, t+1)=\frac{\Delta W_{h}}{\Delta W_{\text {sum }}} Q
$$

It can be seen from formula (11) that $\Delta \tau_{g h}^{k}(t, t+1)$ depends on the cumulative deformation difference between tensioning phases $F_{k}$ and $F_{k+1}$ when the ant arrives at measuring point $h$. In other words, the value of $\Delta \tau_{g h}^{k}$ is positively correlated with that of $\Delta W_{h}$. Hence, the greater the cumulative deformation difference when ant $k$ moves from point $g$ to point $h$, the higher the pheromone concentration on path $(g, h)$, and the easier it is for this path to attract ants. As the pheromone evaporates on each path over time, the pheromone concentration on path $(g, h)$ at time $t+1$ can be defined as

$$
\tau_{g h}(t+1)=(1-\rho) \tau_{g h}(t)+\sum_{k=1}^{m} \Delta \tau_{g h}^{k}(t)
$$

Obviously, the value of $\tau_{g h}(t)$ is positively correlated with the likelihood for ant $k$ to move from point $g$ to point $h$ and the times that it arrives at point $h$ (i.e., the future deformation at point $h$ ).

By using the parallel distributed search capability of ant colony algorithm, several ants are placed in the girder deformation area. These ants are ordered to search and update pheromones based on the aforementioned path selection mechanism and pheromones updating mechanism and also take self-organizing evolution of the algorithm.

At the end of the ant search, the number of times the ants arrive at each measuring point between tensioning phases $F_{k-2}$ and $F_{k-1}$ can be expressed as

$$
f_{F_{k-1}}\left(L_{i}\right)=\left(f_{F_{k-1}}\left(L_{1}\right), f_{F_{k-1}}\left(L_{2}\right), \ldots, f_{F_{k-1}}\left(L_{N}\right)\right)
$$

The total number of times the ants arrive at all measuring points is denoted as $f_{F_{k-1}}^{\text {sum }}=\sum_{i=1}^{N} f_{F_{k-1}}\left(L_{i}\right)$. Then, the predicted deformation difference of each measuring point between tensioning phases $F_{k-1}$ and $F_{k}$ can be calculated as [19]

$$
\begin{aligned}
& \Delta \widehat{W}_{F_{k}}\left(L_{i}\right) \\
& =\frac{\Delta W_{F_{k-1}}^{\text {sum }}}{f_{F_{k-1}}^{\text {sum }}}\left(f_{F_{k-1}}\left(L_{1}\right), f_{F_{k-1}}\left(L_{2}\right), \ldots, f_{F_{k-1}}\left(L_{N}\right)\right)
\end{aligned}
$$

where $\Delta W_{F_{k-1}}^{\text {sum }}$ is the total deformation difference of all measuring points between tensioning phases $F_{k-2}$ and $F_{k-1}$; that is, $\Delta W_{F_{k-1}}^{\text {sum }}=\sum_{i=1}^{N} \Delta W_{F_{k}}\left(L_{i}\right)$.

Then, obtain the predicted cumulative deformation in tensioning phase $F_{k}$ by adding up $\Delta \widehat{W}_{F_{k}}\left(L_{i}\right)$ and $W_{F_{k-1}}\left(L_{i}\right)$ :

$$
\widehat{W}_{F_{k}}\left(L_{i}\right)=\Delta \widehat{W}_{F_{k}}\left(L_{i}\right)+W_{F_{k-1}}\left(L_{i}\right)
$$

where $W_{F_{k-1}}\left(L_{i}\right)$ is the measured deformation values of measuring point $i$ in tensioning phase $F_{k-1}$.

2.3. Parameters Selection Method of Ant Colony Algorithm. The performance of ant colony algorithm prediction model is affected by parameters $m, Q, \alpha, \beta$, and $\rho$; the global search ability and convergence speed of ant colony algorithm should be considered to find the parameters' optimal values. At present, the selection methods of these parameters are not yet determined, and there is still no general method to determine the optimal parameter combination. The optimal combination of the parameters in this paper is determined based on the "three-step" method summarized by [12]; it is calculated out after many times' trial. The specific steps are as follows.

Step 1. Determine the ants' total number $m$. A larger number of ants can improve the global search ability and the stability of algorithm, but at the same time, it can make the pheromones concentration change at path evener and decrease the positive feedback effect of the algorithm. According to the experience, the performance of the algorithm is more balanced when the ratio of city size $N$ to the number of ants $m$ is around 3/2, and the number of ants is determined based on it.

Step 2. Adjust the parameters with a larger value range in turn; they are $Q, \alpha$, and $\beta$. Set $Q \in[1,10000]$ and the step length is 50 ; set $\alpha, \beta \in[0,5]$ and the step length is 0.5 .

Step 3. Adjust the parameter $\rho$ which has a smaller value range. Set $\rho \in(0,1)$, and the iterative step length is 0.1 .

Ant colony algorithm prediction model can realize the prediction of the main girder deformation in the third equal interval tensioning phase with only two sets of deformation measured values at adjacent equal interval phases as input data. Because there might be large difference between the predicted deformation values of ant colony algorithm and the measured values, it is necessary to take a step further to use 
the residual correction model to modify the model and make up for the defect of low accuracy and poor adaptability of single prediction model.

\section{Residual Combination Correction Model}

Generally, the residual sequence of the main girder deformation is usually alternatively positive and negative and has periodicity which is not so regular. This phenomenon means the original data column has some random components and periodic components. In order to further improve the prediction accuracy of the model, generated by harmonic variation, the periodic sequence function and sine function are used to modify the model, and the former can reflect most of the periodic components of the residual sequence waveform, while the latter can reflect the remaining small fraction of random fluctuations in the waveform and be supplement to the former [20]. The concrete implementation steps of the residual composite correction model are as follows.

Step 1. Build residual sequence in $F_{\mathrm{k}}$ tension phase. Assume the longitudinal sequence of the bridge floor measurement point positions is

$$
L_{i}=\left(L_{1}, L_{2}, \ldots, L_{n}\right)
$$

So, residual sequence of $F_{\mathrm{k}}$ tensioning phase is as follows:

$$
E_{F_{k}}\left(L_{i}\right)=W_{F_{k}}\left(L_{i}\right)-\widehat{W}_{F_{k}}\left(L_{i}\right)
$$

In the formula, $W_{F_{k}}\left(L_{i}\right)$ and $\widehat{W}_{F_{k}}\left(L_{i}\right)$, respectively, represent the measured value and predicted value of the measurement point $i$ in the $\mathrm{F}_{\mathrm{k}}$ tension phase.

Step 2. Fit $E_{F_{k}}\left(L_{i}\right)$ by sinusoidal function $\widehat{E} 1_{F_{k}}\left(L_{i}\right)$ generated by the average characteristics of the residual sequence waveform.

$$
\widehat{E} 1_{F_{k}}\left(L_{i}\right)=A \sin \left(\frac{2 \pi L_{i}}{T}+\pi\right)
$$

In the formula, $A=(1 / n) \sum_{i=1}^{n}\left|E_{F_{k}}\left(L_{i}\right)\right| ; T$ is the average of the residual sequence $E_{F_{k}}\left(L_{i}\right)$ wave time span; its value follows the principle of the minimum quadratic sum $J 1_{\text {min }}$ of the fitting values residual for sine function; that is, $J 1_{\min }=$ $\min \left\{J 1_{1}, J 1_{2}, \ldots, J 1_{\mathrm{i}}, \ldots, J 1_{\mathrm{n}},\right\} \quad$ and $J 1_{\mathrm{i}}=\sum_{i=1}^{n}\left[E_{F_{k}}\left(L_{i}\right)-\right.$ $\left.\widehat{E} 1_{F_{k}}\left(L_{i}\right)\right]^{2}$.

Step 3. Fit $E_{F_{k}}\left(L_{i}\right)$ by periodic sequence function $\widehat{E} 2_{F_{k}}\left(L_{i}\right)$ generated by harmonic change.

$$
\widehat{E} 2_{F_{k}}\left(L_{i}\right)=a_{0}+\sum_{j=1}^{\varsigma}\left[a_{j} \cos \left(\omega_{j} L_{i}\right)+b_{j} \sin \left(\omega_{j} L_{i}\right)\right]
$$

where $\omega_{j}=2 j \pi / L_{n}, a_{0}=(1 / n) \sum_{i=1}^{n} E_{F_{k}}\left(L_{i}\right), a_{j}=(2 / n)$ $\sum_{i=1}^{n} E_{F_{k}}\left(L_{i}\right) \cos \left(\omega_{j} L_{i}\right), b_{j}=(2 / n) \sum_{i=1}^{n} E_{F_{k}}\left(L_{i}\right) \sin \left(\omega_{j} L_{i}\right)$.
Step 4. Introduce the weight coefficient $\gamma(0 \leq \gamma \leq 1)$ and pair (18) and (19) to combine the weights, and the residual composite correction value $\widehat{E}_{F_{k}}\left(L_{i}\right)$ is obtained.

$$
\begin{aligned}
\widehat{E}_{F_{k}}\left(L_{i}\right)=(1-\gamma) E 1_{F_{k}}\left(L_{i}\right)+\gamma E 2_{F_{k}}\left(L_{i}\right) & \\
& \\
i & =1,2, \ldots, n
\end{aligned}
$$

In the formula, the value of $\zeta$ and $\gamma$ follows the principle of the minimum quadratic sum $J 2_{\text {min }}$ of the fitting values residual by the periodic function generated by harmonic transform and sine function; that is, $J 2_{\min }=$ $\min \left\{J 2_{1}, J 2_{2}, \ldots, J 2_{\mathrm{i}}, \ldots, J 2_{\mathrm{n}},\right\}$ and $J 2_{\mathrm{i}}=\sum_{i=1}^{n}\left[E_{F_{k}}\left(L_{i}\right)-\right.$ $\left.\widehat{E}_{F_{k}}\left(L_{i}\right)\right]^{2}$.

Step 5. Based on the nearby principle of data, the most recent data can reflect the nature of main girder deformation. $F_{k+1}$ phase prediction value is revised by the fitting value of the residual sequence at $\mathrm{F}_{\mathrm{k}}$ phase [21]. Like that, add up the ant colony algorithm model prediction value $\widehat{W}_{F_{k+1}}\left(L_{i}\right)$ and the correction value $\widehat{E}_{F_{k}}\left(L_{i}\right)$; the prediction value of the final ant colony algorithm correction model is obtained as follows:

$$
\widehat{W} 1_{F_{k+1}}\left(L_{i}\right)=\widehat{W}_{F_{k+1}}\left(L_{i}\right)+\widehat{E}_{F_{k}}\left(L_{i}\right)
$$

\section{The Specific Implementation Steps of the Ant Colony Algorithm Correction Model}

Step 1. Initialize the parameters $Q, \alpha, \beta$, and $\rho$.

Step 2. Determine the initial position of ants. First of all, according to the number of measuring points $N$, determine the scale of ant colony (assume the total number of ants is $m$ ). Then, calculate the deformation difference between each measuring point in the two adjacent tensioning phases. According to the order of values, assign $m$ ants to the measuring points from large to small and determine the initial locations of ants.

Step 3. Calculate the initial information function $\tau_{\text {gh }}(0)$ (formula (9)), the heuristic function $\eta_{\mathrm{gh}}(\mathrm{t})$ (formula (10)), and the state transition probability $P_{g h}^{k}(t)$ (formula (2)), determine the measuring points that the ants will attain in next station, update the pheromones continuously according to rules of formula (12), and record the number of times that the ants arrive at each measuring point by the taboo table Tabu.

Step 4. After the termination of search, the predicted deformation values of measuring points in next phase can be calculated by formulae (14) and (15). If the measuring points in the predicted area are not many, it is advisable to set all $m$ ants to be polymerized to a certain measuring point as an end condition. If the measuring points are many, it is best to set most ants to be polymerized to a measuring point as an end search condition [19].

Step 5. According to a certain step length, parameter $T$ is set, and the sine function (formula (18)) is used to correct 


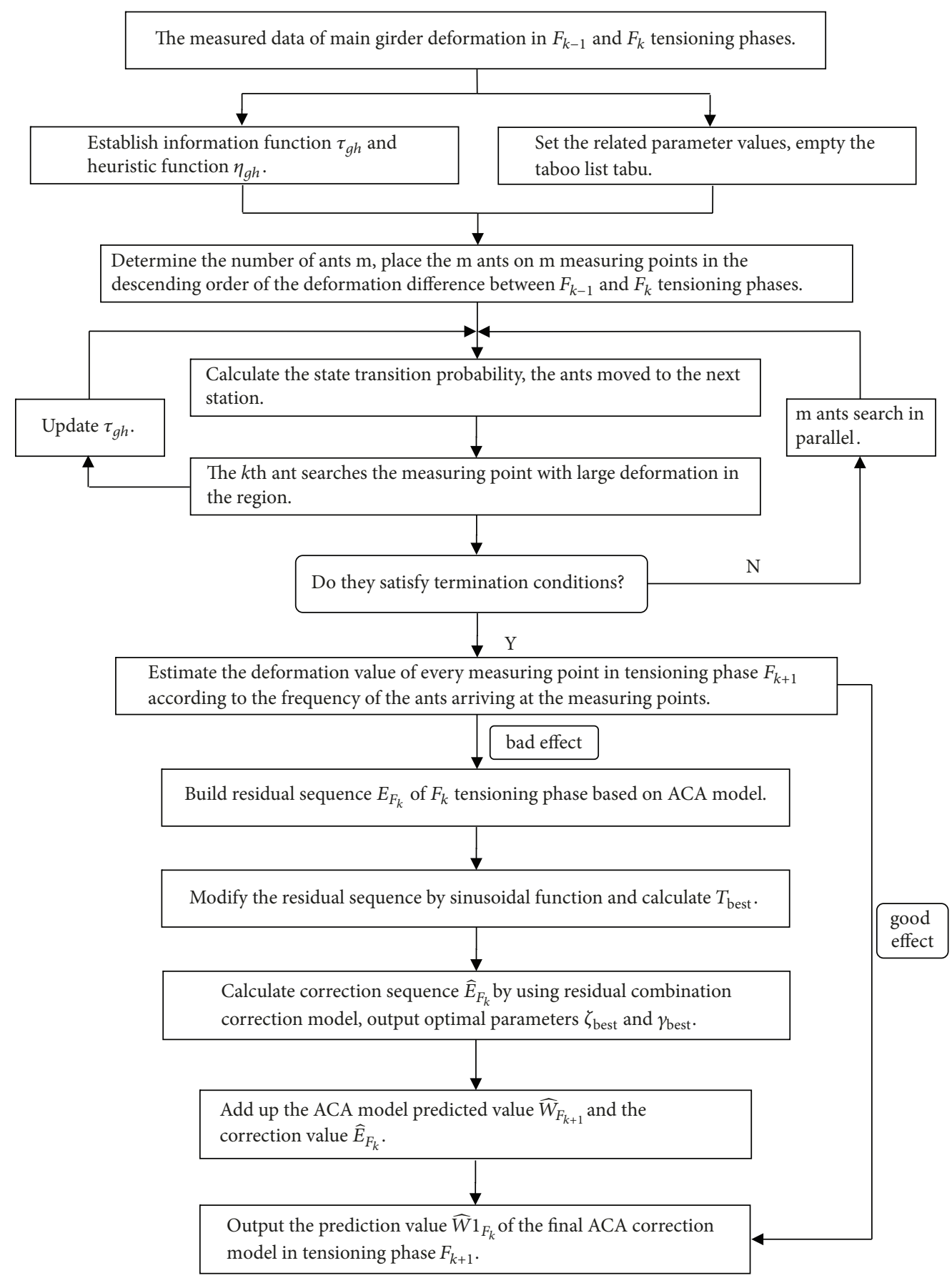

FIGURE 1: Deformation prediction flowchart of SCS-enhanced main girder in tensioning phase by ACA correction model.

the residual sequence $E_{F_{k}}$, and $T_{\text {best }}$ corresponding to the minimum value of the cumulative residual error is output.

Step 6. Select $T=T_{\text {best }}$ and set parameters $\zeta, \gamma$ according to a certain step length. The residual combination correction model is used to modify the residual sequence, and the correction sequence $\widehat{E}_{F_{k}}$ (formula (20)), $\zeta_{\text {best }}$ and $\gamma_{\text {best }}$ corresponding to the minimum value of the cumulative residual error are output.
Step 7. Add up the ant colony algorithm model prediction value $\widehat{W}_{F_{k+1}}$ and correction value $\widehat{E}_{F_{k}}$; the final correction model prediction value $\widehat{W} 1_{F_{k+1}}$ can be obtained by formula (21).

The flowchart of deformation forecasting process of SCSenhanced main girder in tensioning phase by ACA correction model is shown in Figure 1. 


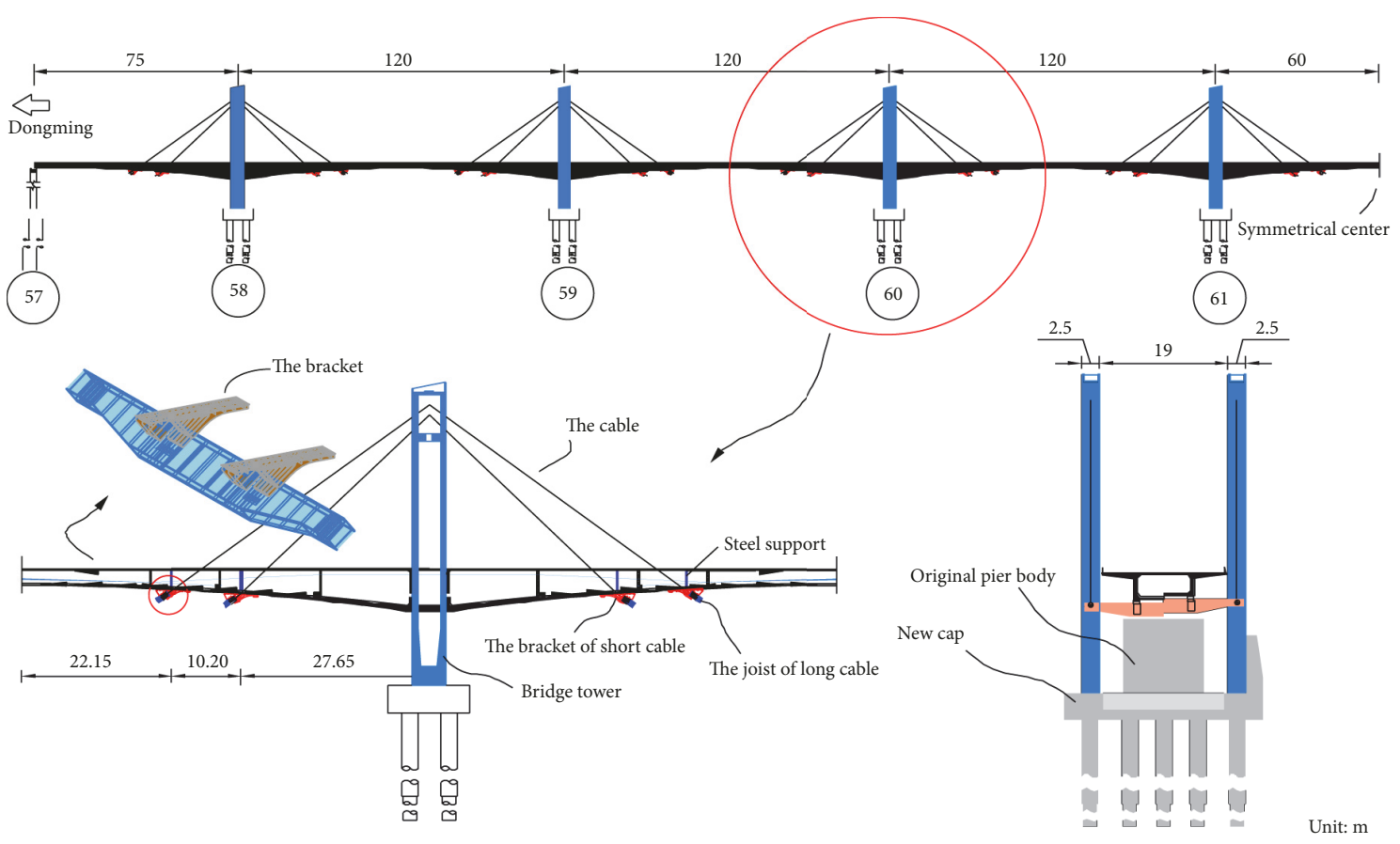

FIgURE 2: Strengthening of Dongming Huanghe River Highway Bridge by application of a stay cable system.

\section{Example Analyzing}

5.1. Project Profile. The main bridge of Dongming Huanghe River Highway Bridge belongs to PSC continuous rigid frame-continuous beam composite structure system; it has nine holes and one link, and the cross-diameter combination is $(75+7 \times 120+75) \mathrm{m}$ with a total length of $990 \mathrm{~m}$. The main girder and the bridge pier are poured with $\mathrm{C} 50$ and C25 concrete, respectively. To curb the excessive deformation and web cracking, the main girder was enhanced in 2003 by increasing the thickness of the web and adding external tendons. Nevertheless, new cracks and deformation were observed in some of the spans of the main bridge after the enhancement. In order to effectively improve the stress condition of the main bridge and raise the height of the midspan section, it was proposed to reinforce this bridge by the cable-stayed system in 2014, and this bridge was the first PSC continuous box girder bridge reinforced by this project in China [3]. The specific connection construction of the bridge tower, the main beam, and the cable were as follows: the top part of the bridge tower was set as a fixed end of the cable by installing the steel anchor boxes and the sliding cable saddles. The trimmer beams, which were set laterally beneath the main girder, were attached to the main girder by based plates on the bottom of the box girder. The stay cable force was transmitted to the main beam through the cooperation of trimmer beams and based plates, as shown in Figure 2. From the middle towers (61\# and 62\#) to the side towers (58\# and 65\#), from the long cables to the short cables, cables were tensioned symmetrically by 8 lifting jacks by level during the tension construction. After tensioning construction, the actual tensioning cable values of short and long cables are $90 \%$ of the design cable values of the bridge, namely, $1,890 \mathrm{kN}$ and $2,430 \mathrm{kN}$. On the basis of the tensioning values of short cables $(630 \mathrm{kN}, 1,155 \mathrm{kN}, 1,365 \mathrm{kN}, 1,575 \mathrm{kN}$, and $1,785 \mathrm{kN}$ ), predicted results are analyzed and studied in this article.

In order to grasp the deformation of the main bridge during the tensioning phases, 46 vertical displacement measuring points were set on the upstream and downstream of the whole bridge. This paper selects the upstream monitoring data to study, as shown in Table 1.

\subsection{Analysis Results}

5.2.1. Analysis Results of ACA Correction Model. This paper selects the measuring deformation data of $1,575 \mathrm{kN}$ and $1,365 \mathrm{kN}$ tensioning phases and predict the deformation in $1,785 \mathrm{kN}$ tensioning phase $\widehat{W} 1_{1,785}$ by ant colony algorithm model. First, the deformation difference of 23 measuring points between the $1,575 \mathrm{kN}$ and $1,365 \mathrm{kN}$ tensioning phases can be calculated as follows:

$\Delta W_{1,575}\left(L_{i}\right)=W_{1,575}\left(L_{i}\right)-W_{1,365}\left(L_{i}\right)=(0.28,1.57,3.67$, 2.73, 0.51, 1.84, 1.94, 0.71, 4.27, 1.63, 1.78, 3.99, 2.00, 0.36, 3.32, $0.53,0.69,2.71,0.35,1.36,5.63,1.57,0.18)$.

Then, determine the number of ants $m=2 N / 3 \approx 15$, sort the $m$ ants in descending order of $\Delta W_{1,575}\left(L_{i}\right)$, and initialize the measuring points $\mathrm{C} 2, \mathrm{C} 3, \mathrm{C} 4, \mathrm{C} 6, \mathrm{C} 7, \mathrm{C} 9, \mathrm{C} 10, \mathrm{C} 11, \mathrm{C} 12, \mathrm{C} 13$, C15, C18, C20, C21, C22 of 15 ants. The deformation of the main girder is predicted by programming; after multiple tests, it is determined that the overall performance of the ant colony algorithm prediction model is more balanced when $Q=5000$, $\alpha=3.0, \beta=4.0$, and $\rho=0.2$. 
TABLE 1: Vertical deformation of the measuring points under different tensioning phases.

\begin{tabular}{|c|c|c|c|c|c|c|}
\hline \multirow{2}{*}{ Measured points } & \multirow{2}{*}{ Distance from $57 \#$ pier center $L / \mathrm{m}$} & \multicolumn{5}{|c|}{ Vertical deformation $W / \mathrm{mm}$} \\
\hline & & $630 \mathrm{kN}$ & $1,155 \mathrm{kN}$ & $1,365 \mathrm{kN}$ & $1,575 \mathrm{kN}$ & $1,785 \mathrm{kN}$ \\
\hline $\mathrm{C} 1$ & 37.5 & -9.13 & -8.48 & -7.73 & -7.45 & -6.31 \\
\hline $\mathrm{C} 2$ & 105.0 & 17.77 & 21.76 & 22.82 & 24.39 & 27.79 \\
\hline $\mathrm{C} 3$ & 135.0 & 35.82 & 44.65 & 47.25 & 50.92 & 52.25 \\
\hline $\mathrm{C} 4$ & 165.0 & 17.77 & 20.21 & 22.66 & 25.39 & 27.12 \\
\hline C5 & 225.0 & 4.58 & 7.53 & 9.35 & 9.86 & 10.97 \\
\hline C6 & 255.0 & 20.61 & 33.27 & 35.11 & 37.87 & 37.87 \\
\hline $\mathrm{C} 7$ & 285.0 & 7.38 & 12.18 & 13.01 & 14.95 & 16.84 \\
\hline $\mathrm{C} 8$ & 345.0 & 7.55 & 7.96 & 8.23 & 8.94 & 10.48 \\
\hline C9 & 375.0 & 17.73 & 23.69 & 26.57 & 30.84 & 32.51 \\
\hline $\mathrm{C} 10$ & 405.0 & 9.10 & 11.75 & 13.58 & 15.21 & 16.99 \\
\hline C11 & 465.0 & 7.56 & 9.27 & 9.76 & 11.54 & 12.18 \\
\hline $\mathrm{C} 12$ & 495.0 & 16.11 & 21.31 & 23.82 & 27.81 & 29.44 \\
\hline $\mathrm{C} 13$ & 525.0 & 5.54 & 7.52 & 8.15 & 10.15 & 11.66 \\
\hline $\mathrm{C} 14$ & 585.0 & 7.61 & 9.82 & 9.99 & 10.35 & 10.38 \\
\hline $\mathrm{C} 15$ & 615.0 & 18.98 & 24.76 & 27.17 & 30.49 & 32.11 \\
\hline $\mathrm{C} 16$ & 645.0 & 7.03 & 8.16 & 8.53 & 9.06 & 9.25 \\
\hline $\mathrm{C} 17$ & 705.0 & 8.04 & 12.64 & 13.33 & 14.02 & 16.45 \\
\hline $\mathrm{C} 18$ & 735.0 & 16.48 & 25.34 & 28.77 & 31.48 & 33.20 \\
\hline $\mathrm{C} 19$ & 765.0 & 4.18 & 8.05 & 9.68 & 10.03 & 11.45 \\
\hline C20 & 825.0 & 11.92 & 15.06 & 15.37 & 16.73 & 17.88 \\
\hline C21 & 855.0 & 25.30 & 33.27 & 37.15 & 42.78 & 45.18 \\
\hline C22 & 885.0 & 11.05 & 16.29 & 17.88 & 19.45 & 21.57 \\
\hline $\mathrm{C} 23$ & 952.5 & 6.09 & 7.83 & 8.06 & 8.24 & 8.26 \\
\hline
\end{tabular}

When all the ants reach the detection point C21, the search terminates, and the number of times the ants arrive at each measuring point is as follows:

$f_{1,575}\left(L_{i}\right)=\left(f_{1,575}\left(L_{1}\right), f_{1,575}\left(L_{2}\right), \cdots, f_{1,575}\left(L_{23}\right)\right)=(0,14$, $15,15,0,15,15,23,15,14,11,15,15,0,15,0,12,15,0,13,30,3,0)$.

According to formula (14), the predicted deformation difference between tensioning phases $1,785 \mathrm{kN}$ and $1,575 \mathrm{kN}$ is as follows:

$\Delta \widehat{W}_{1,785}\left(L_{i}\right)=\Delta W_{1,575}^{\text {sum }} \cdot f_{1,575}\left(L_{i}\right) / f_{1,575}^{\text {sum }}=43.62 \times$ $f_{1,575}\left(L_{i}\right) / 255=(0.00,2.39,2.57,2.57,0.00,2.57,2.57,3.93,2.57$, $2.39,1.88,2.57,2.57,0.00,2.57,0.00,2.05,2.57,0.00,2.22,5.13$, $0.51,0.00)$.

According to formula (15), the predicted deformation in the $1,785 \mathrm{kN}$ tensioning phase is as follows:

$\widehat{W}_{1,785}\left(L_{i}\right)=\Delta \widehat{W}_{1,785}\left(L_{i}\right)+W_{1,575}\left(L_{i}\right)=(-7.45,26.78,53.49$, $27.96,9.86,37.68,17.52,12.87,33.41,17.60,13.42,30.38,12.72$, $10.35,33.06,9.06,16.07,34.05,10.03,18.95,47.91,19.96,8.24)$.

Based on the prediction model of ant colony algorithm, the residual sequence is as follows:

$E_{1,785}\left(L_{i}\right)=W_{1,785}\left(L_{i}\right)-\widehat{W}_{1,785}\left(L_{i}\right)=(1.14,1.01,-1.24,-0.84$, $1.11,-0.44,-0.68,-2.39,-0.90,-0.61,-1.24,-0.94,-1.06,0.03$, $0.95,0.19,0.38,-0.85,1.42,-1.07,-2.73,1.61,0.02)$.

There is a certain deviation between the predicted and measured deformation values in the $1,785 \mathrm{kN}$ tensioning phase. This is attributable to the following two reasons.
First, the ants are not sensitive to the measuring points with small deformation in the early phase; thus, some measuring points are not visited by the ants, leading to a large residual value. Second, it can be seen from the calculation results of the residual sequence of $1,785 \mathrm{kN}$ tensioning phase that this residual sequence is usually alternatively positive and negative and has periodicity which is not so regular. This phenomenon means the original data column has some random components and periodic components.

In order to further improve the prediction accuracy of the ant colony algorithm prediction model, this paper takes fitting calculation on residual sequence of $1,575 \mathrm{kN}$ tensioning phase by residual combination correction model and takes it as the correction sequence of the predicted value of the $1,785 \mathrm{kN}$ tensioning phase.

Firstly, based on the ant colony algorithm prediction model, the deformation prediction value $\widehat{W}_{1,575}$ of $1,575 \mathrm{kN}$ tensioning phase is obtained as follows:

$\widehat{W}_{1,575}=(-5.64,24.91,49.34,24.75,11.44,35.36,15.10,8.23$, 28.66, 13.86, 9.76, 25.91, 9.27, 9.99, 28.57, 8.53, 16.68, 30.86, $11.77,15.51,41.34,19.97,8.06)$.

Then, the residual sequence is as follows:

$E_{1,575}=(1.81,0.52,-1.58,-0.64,1.58,0.25,0.15,-0.71,-2.18$, $-1.35,-1.78,-1.90,-0.88,-0.36,-1.92,-0.53,2.66,-0.62,1.74$, $1.22,-1.44,0.52,-0.18)$. 


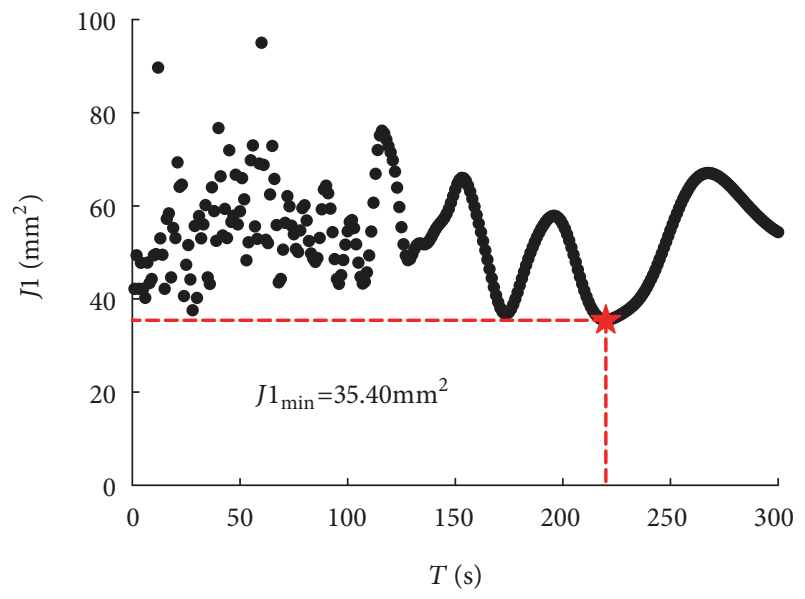

FIGURE 3: Relation graph between parameter $T$ and the residual quadratic sum J1.

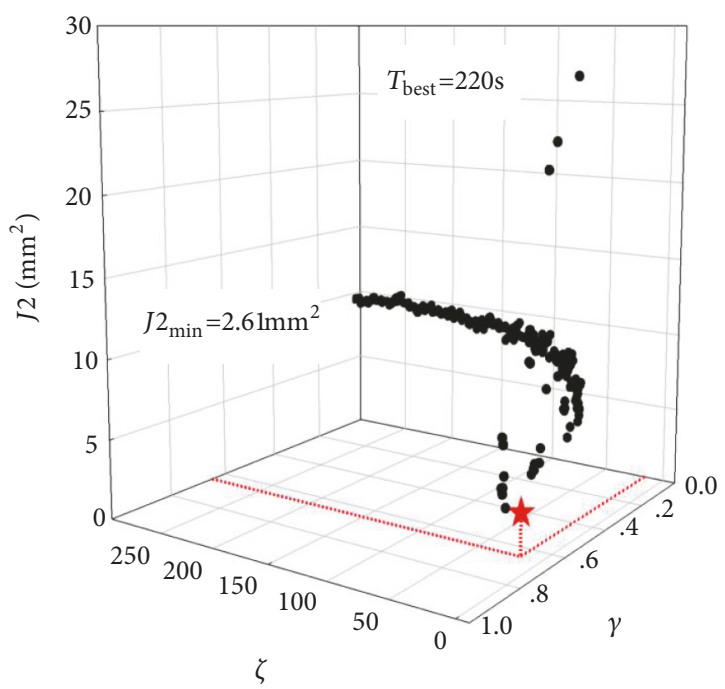

FIgURE 4: Relation graph between parameters $\zeta, \gamma$ and the residual quadratic sum $\mathrm{J} 2$ under $T_{\text {best }}=220 \mathrm{~s}$.

Secondly, the residual sequence is modified by sine function, and the parameter $T_{\text {best }}$ is calculated. Set $T \in$ $[1,10000]$ and the step length is 1 ; take iterative computation. When $T=220 \mathrm{~s}, J 1_{\min }=35.40 \mathrm{~mm}^{2}$, the calculation result is best. The first 300 iteration results are shown in Figure 3.

Then, the periodic sequence function and sine function generated by harmonic variation are used to modify the residual sequence in combination. Set $\zeta \in[1,10000]$ and the step length is 1; take iterative computation. When $T=220 \mathrm{~s}$, $\zeta=15$ and $\gamma=0.65, J 2_{\min }=2.61 \mathrm{~mm}^{2}$, the calculation result is best; the first 300 iteration results are shown in Figure 4.

So, the correction sequence of the $1,785 \mathrm{kN}$ tensioning phase is as follows:

$\widehat{E}_{1,575}=W_{1,575}\left(L_{i}\right)-\widehat{W}_{1,575}\left(L_{i}\right)=(1.05,0.97,-1.67,-0.69$, $1.86,0.18,0.77,-2.47,-2.70,-1.37,-0.92,-1.64,-0.17,-0.36,-2.29$, $0.37,-1.01,-0.41,1.81,-1.30,-1.47,0.55,-0.27)$.

Finally, the deformation under the ant colony algorithm correction model is obtained by formula (21) as follows:
$\widehat{W} 1_{1,785}\left(L_{i}\right)=\widehat{W}_{1,785}\left(L_{i}\right)+\widehat{E}_{1,575}\left(L_{i}\right)=(-6.40,27.76,51.82$, 27.27, 11.72, 37.86, 18.29, 10.40, 30.71, 16.24, 12.50, 28.74, 12.55, $9.99,30.77,9.43,15.06,33.64,11.94,17.65,46.44,20.51,7.97)$.

5.2.2. Analysis Results of UIGM $(1,1)$ and Its Two Residual Correction Models. This paper regards the cable force data in tensioning phase as the original time sequences, regards the vertical deformation data obtained from the bridge floor survey points as the original date sequences, and builds the prediction model of main girder deformation strengthened by a stay cable system based on UIGM $(1,1)$ [22]. This model takes the deformation data of the first four tension phases of every point as input values and predicts the deformation of the $1,785 \mathrm{kN}$ tensioning phase.

In addition, the modified model provided in $[23,24]$ was adopted to correct the predicted value of $\operatorname{UIGM}(1,1)$. The one-time residual correction UIGM $(1,1)$ (OC - UIGM (1, 1)) is introduced in [23]. During prediction, this model first establishes the UIGM $(1,1)$ model of the residual value and then compensates the original predicted value with the sum of the predicted value of the residual UIGM $(1,1)$ and the original predicted value.

Under various factors, the main girder deformation and its trend cannot be determined completely, which is consistent with the highly random nature of Markov residual prediction. Through Markov residual prediction, it is possible to improve the random features of the sequence and optimize the predicted results. Therefore, the UIGM $(1,1)$ predicted value is modified by the Markov chain in [24].

(1) Predicted Results of OC - UIGM $(1,1)$. Based on the predicted results of UIGM $(1,1)$, the deformation residuals of the first four tensioning phases were calculated. Taking the tensioning force $F_{k}$ as the time sequence and the residual sequence $E_{F_{k}}\left(L_{i}\right)$ is used as the original sequence, UIGM (1, 1) was reestablished to obtain the predicted residual value $\widehat{E}_{F_{k+1}}\left(L_{i}\right)$ of tensioning phase $F_{k+1}$. Finally, the predicted residual values $\widehat{E}_{F_{k+1}}\left(L_{i}\right)$ and $\widehat{W}_{F_{k+1}}\left(L_{i}\right)$ were added to obtain the final predicted value $\widehat{W} 2_{F_{k+1}}\left(L_{i}\right)$.

Here, measuring point $\mathrm{C} 3$ is cited as an example to describe the prediction process. According to the predicted results of UIGM $(1,1)$, the residual sequence of the first four tensioning phases was identified as $E_{F_{k}}\left(L_{i}\right)=(0.00,-0.40,0.46$, 3.11). Then, the UIGM $(1,1)$ was reestablished with $F_{k}=(630$, $1,155,1,365,1,575)$ as the time sequence of the grey model and the residual sequence $(0.00,-0.40,0.46,3.11)$ as the original data sequence. However, the modelling cannot be implemented by the common method, because the sign of the residual sequence is either positive or negative. In light of this, the translation transformation method in [25] was adopted as follows.

Step 1. The residual sequence was transformed into a nonnegative one by adding a translation quantity $\mathrm{H}$.

Step 2. The new residual was predicted again.

Step 3. The predicted value was subtracted by the translation quantity $\mathrm{H}$. 
After substituting (630, 1,155, 1,365 and 1,575) and (5.00, $4.60,5.46$ and 8.11$)$ into the $\operatorname{UIGM}(1,1)$, the residual value was predicted as $6.79 \mathrm{~mm}$ and $1.79 \mathrm{~mm}$ after the translation transformation. follows:

Thus, the modified predicted deformation value is as

$$
\widehat{W} 2_{1,785}=\widehat{W}_{1,785}+\widehat{E}_{1,785}=48.85+1.79=50.64
$$

(2) Predicted Results of Markov Chain Residual Correction $\operatorname{UIGM}(1,1)(M C-\operatorname{UIGM}(1,1))$. Markov chain prediction mainly forecasts the possible state of system variables at a certain time in future according to the current state and the change trend. According to a rational self-made standard, the residual sequence was divided into $n$ states, namely, $S_{1}, S_{2}, \cdots, S_{n}$. Thus, the transition probability of $R$ steps can be expressed as $p_{i k}^{(R)}=M_{i k}^{(R)} / \sum_{k=1}^{n} M_{i k}^{(R)}$, with $M_{i k}^{(R)}$ being the number of data in the residual sequence transferred from state $S_{i}$ to state $S_{k}$ through the $R$ steps and $\sum_{k=1}^{n} M_{i k}^{(R)}$ being the total number of original data in the residual sequence in state $S_{i}$. Then, the state transition matrix can be defined as

$$
P^{(R)}=\left[\begin{array}{cccc}
p_{11}^{(R)} & p_{12}^{(R)} & \cdots & p_{1 n}^{(R)} \\
p_{21}^{(R)} & p_{22}^{(R)} & \cdots & p_{2 n}^{(R)} \\
\vdots & \vdots & & \vdots \\
p_{n 1}^{(R)} & p_{n 2}^{(R)} & \cdots & p_{n n}^{(R)}
\end{array}\right]
$$

where $\sum_{k=1}^{n} P_{i k}^{(R)}=1$.

Generally, the state intervals are classified based on the mean and standard deviations of the data sequence, and the mean $\chi_{i}$ of the two endpoint values of the interval is the centre of the i-th state interval. Here, the residual sequence $E_{F_{k}}\left(L_{i}\right)$ is divided into $\mathrm{n}$ states $\mathrm{S}$, and $\mathrm{r}$ transfer probability vectors are used. Transition probability vectors (the rows of a matrix) are needed to consider the transition processes in $r$ steps. The probability of residual state at the target moment is the sum of the $\mathrm{r}$ vectors, and the vector element is denoted as $\left(\eta_{1}, \eta_{2}, \cdots, \eta_{n}\right)$. Then, the residual correction value of phase $F_{k+1}$ is denoted as $\widehat{M}_{F_{k+1}}\left(L_{i}\right)=\omega_{1} \chi_{1}+\omega_{2} \chi_{2}+\cdots+\omega_{n} \chi_{n}$, where $\omega_{i}=\eta_{i} /\left(\eta_{1}+\eta_{2}+\cdots+\eta_{n}\right)$ is the state weight and $\chi_{i}$ is the centre of the state interval. Therefore, the predicted value of UIGM $(1,1)$, modified by Markov, can be expressed as $\widehat{W} 3_{F_{k+1}}\left(L_{i}\right)=\widehat{W}_{F_{k+1}}\left(L_{i}\right)+\widehat{M}_{F_{k+1}}\left(L_{i}\right)$.

The residual sequence was divided into three state intervals $[\nu-1.9 \sigma, \nu-0.6 \sigma],[\nu-0.6 \sigma, \nu+0.6 \sigma]$, and $[\nu+0.6 \sigma$, $\nu+1.9 \sigma]$ according to the mean $v$ and standard deviation $\sigma$ of the residual sequence of this point. The three state intervals correspond to states $S_{1}, S_{2}$, and $S_{3}$ and cover the entire residual range. For measuring point $\mathrm{C} 3$, the 3 state intervals were $[-0.72,-0.03],[-0.03,1.62]$, and $[1.62,3.40]$, and the corresponding states are shown in Table 2.
TABLE 2: State of residual sequence.

\begin{tabular}{lcc}
\hline Tensioning force $/ \mathrm{kN}$ & Residual $/ \mathrm{mm}$ & State \\
\hline 630 & 0.00 & $S_{2}$ \\
1,155 & -0.40 & $S_{1}$ \\
1,365 & 0.46 & $S_{2}$ \\
1,575 & 3.11 & $S_{3}$ \\
\hline
\end{tabular}

The residual value of the $1,785 \mathrm{kN}$ tensioning phase was predicted by the state transitions of $630 \mathrm{kN} \sim 1,575 \mathrm{kN}$ tensioning phases, with a total of 3 steps of transitions. The state transition matrix can be expressed as

$$
\begin{aligned}
& P^{(1)}=\left[\begin{array}{lll}
0 & 1 & 0 \\
\frac{1}{2} & 0 & \frac{1}{2} \\
0 & 0 & 0
\end{array}\right], \\
& P^{(2)}=\left[\begin{array}{lll}
0 & 0 & 1 \\
0 & 1 & 0 \\
0 & 0 & 0
\end{array}\right], \\
& P^{(3)}=\left[\begin{array}{lll}
0 & 0 & 0 \\
0 & 0 & 1 \\
0 & 0 & 0
\end{array}\right] .
\end{aligned}
$$

Then, the transition probabilities are listed in Table 3.

The state centres were calculated as $\chi_{1}=-0.38, \chi_{2}=0.79$, and $\chi_{3}=2.51$; the state weights were calculated as $\omega_{1}=$ $\eta_{1} / \sum_{i=1}^{n} \eta_{i}=0 / 1=0, \omega_{2}=\eta_{2} / \sum_{i=1}^{n} \eta_{i}=1 / 1=1$, and $\omega_{3}=\eta_{3} / \sum_{i=1}^{n} \eta_{i}=0 / 1=0$. Then, the Markov residual of the $1,785 \mathrm{kN}$ tensioning phase can be derived as

$$
\begin{aligned}
\widehat{M}_{1,785} & =\omega_{1} \cdot \chi_{1}+\omega_{2} \cdot \chi_{2}+\omega_{3} \cdot \chi_{3} \\
& =0 \times(-0.38)+1 \times 0.79+0 \times 2.51=0.79
\end{aligned}
$$

Thus, the final predicted value of the deformation in the said phase is

$$
\widehat{W} 3_{1,785}=\widehat{W}_{1,785}+\widehat{M}_{1,785}=48.85+0.79=49.64
$$

For other measuring points, the deformation in the $1,785 \mathrm{kN}$ tensioning phase can be obtained similarly with the OC model and MC model.

5.2.3. Analysis Results of FEM. The previous studies have attributed the deformation of PSC box girder bridges to the following factors: concrete shrinkage, creep, prestress loss, and the mismatch between actual and theoretical concrete amounts [26, 27]. Excessive deformation of such bridges may exacerbate the cracking and reduce the shear stiffness of box girder web, which, in turn, aggravates the deformation of the main girder.

The deformation features of the SCS-enhanced main girder in the tensioning phase were discussed using the finiteelement software. A finite-element model was established 
TABLE 3: State transition probabilities.

\begin{tabular}{lcccc}
\hline \multirow{2}{*}{ Transition step } & \multirow{2}{*}{ Tensioning force/kN } & State & \multicolumn{2}{c}{ Transition probability } \\
\hline 1 & 1,575 & $S_{1}$ & 0 & $S_{2}$ \\
2 & 1,365 & $S_{2}$ & 0 & 0 \\
3 & 1,155 & $S_{1}$ & 0 & 0 \\
\hline
\end{tabular}

TABLE 4: Diagonal crack grading standard.

\begin{tabular}{|c|c|c|}
\hline \multirow{2}{*}{ Diagonal crack scale $\mathrm{G}_{\mathrm{i}}$} & \multicolumn{2}{|c|}{ Criteria } \\
\hline & Qualitative description & Quantitative description \\
\hline 1 & There is no diagonal crack. & -- \\
\hline 2 & $\begin{array}{l}\text { There are a few slight diagonal cracks, whose width } \\
\text { falls within the allowable range. }\end{array}$ & The crack length is less than $1 / 3$ of the sectional size. \\
\hline 3 & $\begin{array}{l}\text { There are many diagonal cracks, whose width falls } \\
\text { within the allowable range. }\end{array}$ & $\begin{array}{l}\text { The crack length is between } 1 / 3 \text { and } 1 / 2 \text { of the } \\
\text { sectional size. }\end{array}$ \\
\hline 4 & $\begin{array}{l}\text { There are numerous diagonal cracks, whose width } \\
\text { exceeds the allowable range. }\end{array}$ & $\begin{array}{l}\text { The crack length is greater than } 1 / 2 \text { of the section } \\
\text { size, and the mean crack interval is less than } 30 \mathrm{~cm} \text {. }\end{array}$ \\
\hline 5 & $\begin{array}{l}\text { There are numerous through diagonal cracks, whose } \\
\text { width far exceeds the allowable range. }\end{array}$ & $\begin{array}{l}\text { The crack width is greater than } 1.0 \mathrm{~mm} \text { and the mean } \\
\text { crack interval is less than } 20 \mathrm{~cm} \text {. }\end{array}$ \\
\hline
\end{tabular}

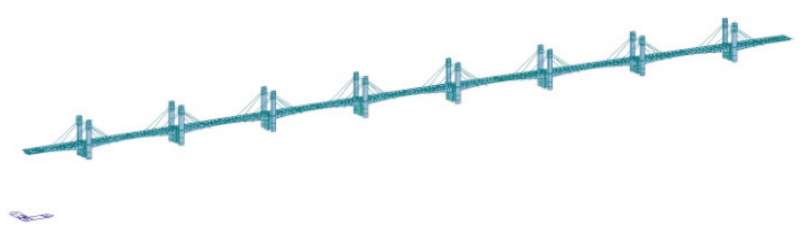

FIGURE 5: Finite element model of main girder strengthening by a SCS.

considering the following factors: (1) the section construction in 1991; (2) the effective prestress of tendon determined by actual measurement and theoretical calculation; (3) timedependent effect of concrete materials; (4) shear stiffness reduction of the web; (5) the addition of external tendons and increase of web thickness in 2003; (6) the mismatch between actual and theoretical concrete amounts; (7) tensioning sequence of stay cables.

In the finite-element model, the main girder was discretized into 347 girder elements, the stay cable into 64 truss elements, and the bridge pier into 312 girder elements. The shrinkage and creep of concrete were simulated according to the Code for Design of Highway Reinforced Concrete and Pre-Stressed Concrete Bridges and Culverts (JTG D62-2004). Elastic connection was adopted between the stay cable and the main girder. The finite-element model is presented in Figure 5.

The deformation increment caused by the diagonal cracks of the web was simulated by the shear stiffness degradation model [28] and the crack grading method [29] through the following steps.

(1) The main bridge was divided into several units. Then, the grade $G_{i}$ of the diagonal cracks in each unit was determined according to the diagonal cracks of the web measured in 2013 [30] and the diagonal crack grading standard (Table 4).

(2) The limit $\lambda_{\mathrm{u}}$ on shear stiffness degradation factor (SSDF) was calculated by the following equation:

$$
\lambda_{u}=\frac{14.4 \rho_{\nu} \cot ^{2} \theta}{1+6 \rho_{v} \csc ^{2} \theta}
$$

where $\rho_{v}$ is the stirrup rate of the web; $\theta$ is the diagonal crack angle.

(3)The SSDFs $\lambda$ were determined for all crack grades. When there is no diagonal crack, the elastic shear stiffness of the web can be determined as $K_{e}=G_{c} A_{v}=E_{c} A_{v} / 2(1+\mu)$, with $G_{c}, E_{c}, A_{v}$, and $\mu(\mu=0.20)$ being the shear modulus, elastic modulus, shear area, and Poisson's ratio of concrete. The SSDF $\lambda$ describes the degradation of shear stiffness in general cracking state $\left(K=\lambda K_{e}\right)$. The value of $\lambda$ can be calculated by

$$
\lambda=1-\frac{\left(1-\lambda_{u}\right)\left(G_{i}-1\right)}{4}
$$

(4) The modified Poisson's ratios were determined for all crack scales:

$$
\mu^{\prime}=\frac{1+\mu}{\lambda}-1=\frac{1.2}{\lambda}-1
$$

(5) The shear stiffness degradation was simulated by modifying Poisson's ratio of each unit in the finite-element model, laying the basis for deformation analysis of the main girder.

The calculated SSDF and modified Poisson's ratio of our example are listed in Table 5.

According to the FEM results, the deformation of the measuring points in the $1,785 \mathrm{kN}$ tensioning phase amounts to 
TABLE 5: Parameter selection for different grade scales of web diagonal cracks.

\begin{tabular}{lcr}
\hline Diagonal crack scale $G_{\mathrm{i}}$ & Shear stiffness degradation factor $\lambda$ & Modified Poisson's ratio $\mu^{\prime}$ \\
\hline 1 & 1.00 & 0.20 \\
2 & 0.79 & 0.52 \\
3 & 0.58 & 1.07 \\
4 & 0.36 & 2.33 \\
5 & 0.15 & 7.00 \\
\hline
\end{tabular}

$\widehat{W}_{1,785}\left(L_{i}\right)=\left(\widehat{W}_{1,785}\left(L_{1}\right), \widehat{W}_{1,785}\left(L_{2}\right), \ldots, \widehat{W}_{1,785}\left(L_{23}\right)\right)$

$=(9.60,24.92,46.90,23.40,10.56,31.92,13.30,8.83,27.27,15.39,11.96,26.94,9.48,8.14,26.62,7.07,14.96,28.97,9.23,14.11,37.89,21.28,7.51)$.

The FEM predicted value was contrasted with the value measured in the $1,785 \mathrm{kN}$ tensioning phase, revealing that it deviated from the measured value by $23.83 \%$. The deviation comes from two possible reasons. First, the FEM failed to simulate the deformation of measuring point $\mathrm{Cl}$ in the $630 \mathrm{kN}$ tensioning phase, leading to a $252.19 \%$ error between the predicted and measured values in the $1,785 \mathrm{kN}$ tensioning phase. Second, the established model did not consider the deformation increment that resulted from the longterm structural damage under vehicle load, bar corrosion, prestressed tendon corrosion, and temperature effect. The predicted values of all measuring points other than $\mathrm{Cl}$ were smaller than the measured values. The variation trends of the measuring points were consistent and the mean relative error was $13.45 \%$.

The deformation values and relative error obtained by six models are as shown in Table 6. Among them, the calculation of relative error in Table 6 was explained as $100 \times\left[W_{F_{k}}\left(L_{i}\right)-\right.$ $\left.\widehat{W}_{F_{k}}\left(L_{i}\right)\right] / W_{F_{k}}\left(L_{i}\right)$.

In order to reflect the data in Table 6 more intuitively, the data are represented in Figures 6 and 7 as graphs. The absolute deviation of predicted values to the measured values in graph 6 is magnified 5 times larger; that is, the ordinate values were recalculated by $5 \times\left[\widehat{W}_{F_{k}}\left(L_{i}\right)-W_{F_{k}}\left(L_{i}\right)\right]+W_{F_{k}}\left(L_{i}\right)$. Figure 7 draws relationship curves of three models with smaller mean absolute error (MAE), and MAE was calculated by the following equation:

$$
\varepsilon=100 \times \frac{1}{N} \sum_{i=1}^{N}\left|\frac{\left[W_{F_{k}}\left(L_{i}\right)-\widehat{W}_{F_{k}}\left(L_{i}\right)\right]}{W_{F_{k}}\left(L_{i}\right)}\right|
$$

The prediction models were contrasted and evaluated from three aspects: the measured datasets for modelling (MDM), the time consumption, and the mean absolute error (MAE), as shown in Table 7.

It can be concluded from Table 7 that the $\operatorname{UIGM}(1,1)$, the MC-UIGM $(1,1)$, and the $\operatorname{OC}-\operatorname{UiGM}(1,1)$ have the lowest prediction accuracy, the mean absolute error is $12.51 \%$, $8.40 \%$, and $8.01 \%$, respectively, the prediction accuracy of ant colony algorithm is a little higher, and its mean absolute error is $5.90 \%$. That is because compared with the UIGM $(1,1)$ model and residual correction models, ant colony algorithm prediction model considers both the differences of each measuring point in space position and the tensioning phase characteristics of the measuring point deformation at the same time, and it can better excavate the internal rules of monitoring data and improve the prediction accuracy. After modification, the mean absolute error of ant colony algorithm prediction model is reduced to $3.39 \%$. This is because of that using periodic sequence function and sinusoidal residual correction function generated by harmonic change to modify predicted values in combination can well simulate the trend components and random fluctuation compositions of girder deformation, and it can make up for the defect of the low prediction accuracy of the single model, further improve the prediction accuracy, and enhance the adaptability of the model.

The proposed model enjoys the following advantages over the five contrastive prediction models:

(1) Compared with UIGM $(1,1)$, the model can disclose the deformation trends of multiple correlated measuring points.

(2) Compared with the grey modelling method, the model requires a limited amount of modelling data.

(3) Compared with the four models, the model consumes a very short computing time.

(4) Compared with the five models, the model achieves a very low mean absolute error (3.39\%).

Of course, the model still has some limitations:

(1) Unlike the FEM, the model must be modelled based on the measured data.

(2) The model needs one more dataset than the ACA.

(3) Unlike UIGM $(1,1)$, the model only works when the measured data are continuous and of equal interval.

In order to further determine whether the correction model is reliable for the deformation prediction of the main girder, the model accuracy test is carried out by using statistical posterior error $C$ and small probability $p$ test method [31]. In general, the prediction accuracy of the model is divided into four grades. The value ranges of $C$ and $p$ in each grade are defined, respectively: $C<0.35, p>0.95$ (excellent); $0.35 \leq C<0.5,0.80<p \leq 0.95$ (up to standard); $0.50 \leq C<0.65,0.70<p \leq 0.80$ (reluctant); $C>0.65, p \leq$ 0.70 (below standard). According to the prediction data of 


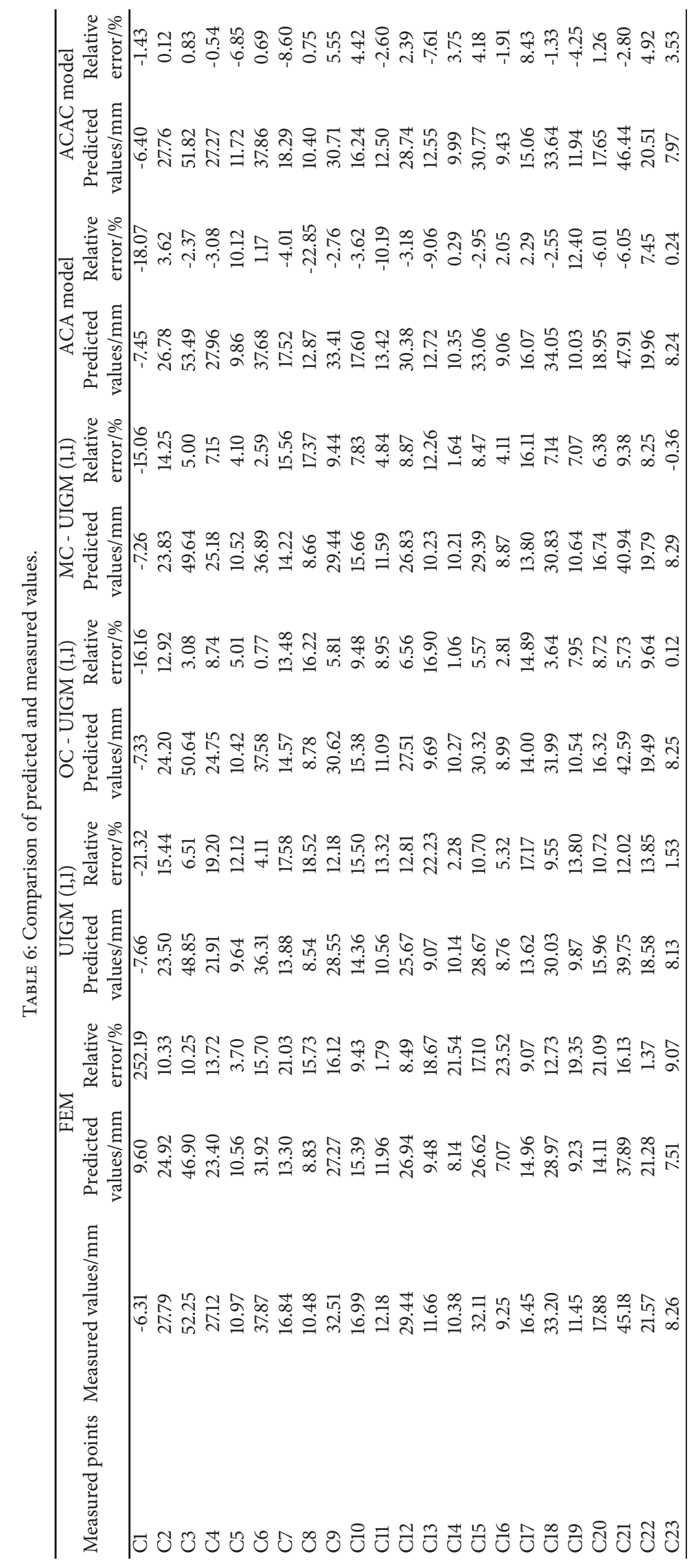




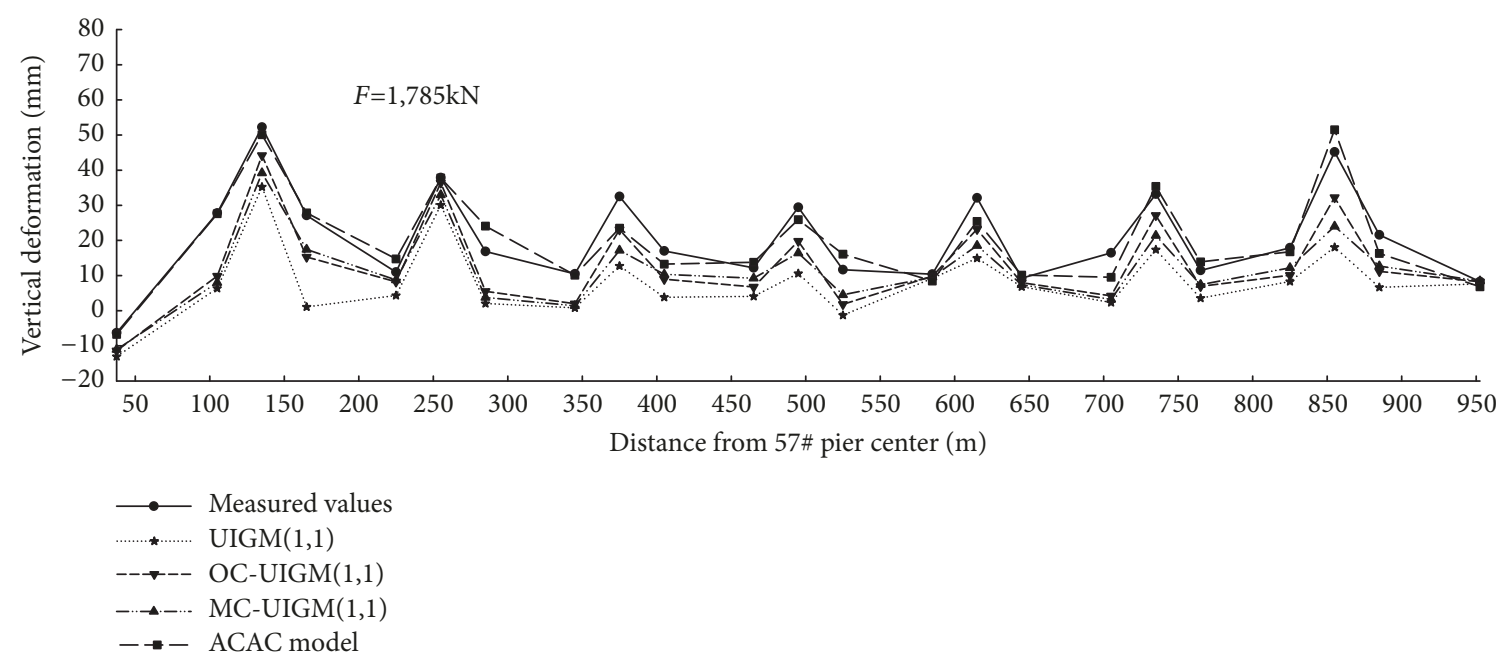

(a)

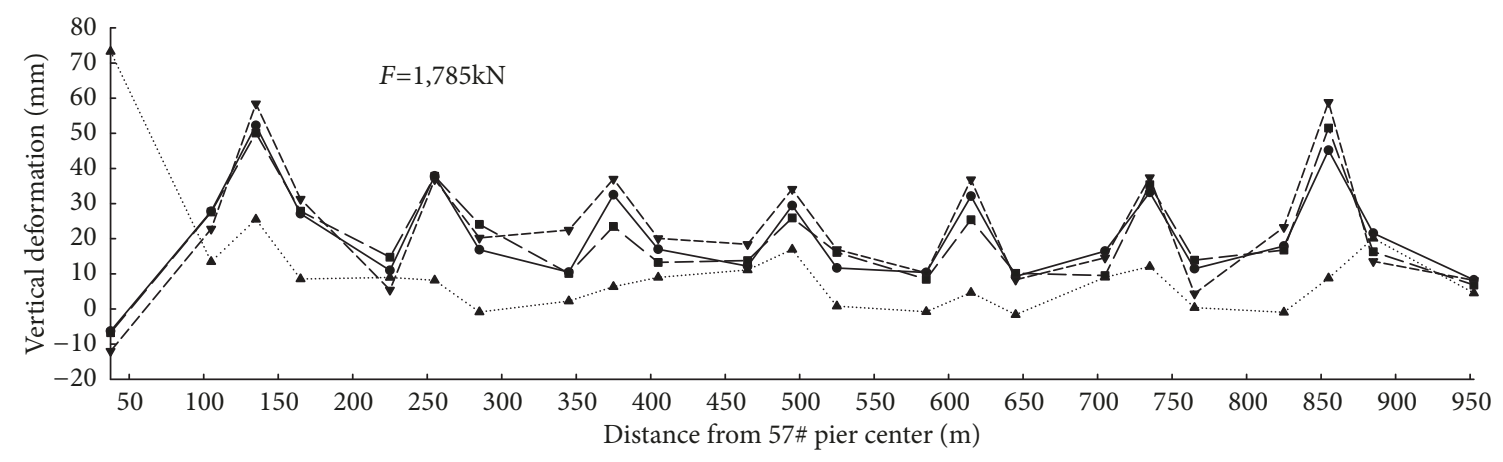

(b)

Figure 6: Predicted results of different models.

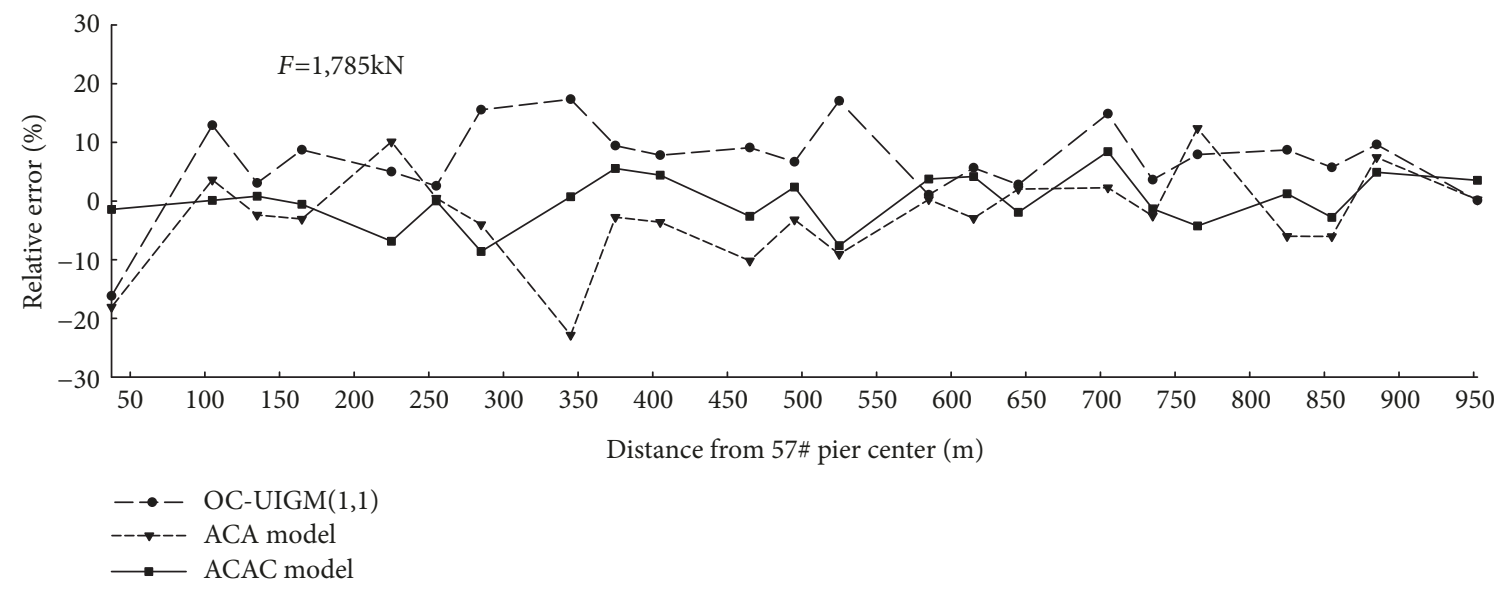

Figure 7: Predicted relative error of three different models. 
TABLE 7: Comparison of evaluation results under different prediction models.

\begin{tabular}{lccc}
\hline Prediction model & MDM & Time consuming/s & MAE/\% \\
\hline FEM & 0 & 1196.87 & 23.83 \\
UIGM $(1,1)$ & 4 & 2.07 & 12.51 \\
OC - UIGM $(1,1)$ & 4 & 4.18 & 8.01 \\
MC - UIGM $(1,1)$ & 4 & 2.76 & 8.40 \\
ACA model & 2 & 0.05 & 5.90 \\
ACAC model & 3 & 0.13 & 3.39 \\
\hline
\end{tabular}

TABLE 8: Comparison of predicted values in $1,995 \mathrm{kN}$ tensioning phase.

\begin{tabular}{|c|c|c|c|c|c|c|}
\hline \multirow{2}{*}{ Measured points } & \multicolumn{6}{|c|}{ Predicted values $/ \mathrm{mm}$} \\
\hline & FEM & $\operatorname{UIGM}(1,1)$ & OC - UIGM $(1,1)$ & MC - UIGM(1,1) & ACA model & ACAC model \\
\hline $\mathrm{C} 1$ & 11.37 & -7.25 & -6.86 & -6.79 & -4.61 & -5.03 \\
\hline $\mathrm{C} 2$ & 28.31 & 24.91 & 25.73 & 25.89 & 31.19 & 30.46 \\
\hline $\mathrm{C} 3$ & 52.93 & 50.30 & 52.47 & 52.63 & 53.95 & 55.27 \\
\hline $\mathrm{C} 4$ & 26.27 & 25.29 & 28.74 & 29.03 & 28.82 & 30.31 \\
\hline C5 & 13.12 & 10.25 & 11.16 & 11.26 & 12.67 & 11.61 \\
\hline C6 & 37.09 & 37.11 & 38.62 & 38.83 & 37.98 & 40.99 \\
\hline C7 & 15.97 & 14.96 & 15.77 & 15.68 & 18.54 & 20.02 \\
\hline $\mathrm{C} 8$ & 11.20 & 9.16 & 9.43 & 9.12 & 10.48 & 13.19 \\
\hline C9 & 32.10 & 30.34 & 32.81 & 32.98 & 32.62 & 33.95 \\
\hline $\mathrm{C} 10$ & 17.90 & 15.44 & 16.64 & 16.93 & 18.69 & 19.81 \\
\hline C11 & 14.29 & 11.22 & 11.83 & 12.42 & 13.88 & 15.22 \\
\hline $\mathrm{C} 12$ & 31.58 & 27.35 & 29.54 & 29.04 & 29.55 & 30.94 \\
\hline $\mathrm{C} 13$ & 11.82 & 10.07 & 10.79 & 11.42 & 12.45 & 13.73 \\
\hline $\mathrm{C} 14$ & 10.55 & 10.25 & 10.40 & 10.38 & 10.38 & 10.67 \\
\hline C15 & 31.24 & 30.14 & 32.10 & 32.25 & 32.22 & 33.43 \\
\hline $\mathrm{C} 16$ & 9.29 & 8.96 & 9.23 & 9.30 & 12.20 & 11.85 \\
\hline C17 & 17.60 & 14.52 & 14.97 & 15.02 & 18.15 & 18.46 \\
\hline $\mathrm{C} 18$ & 34.01 & 31.47 & 33.85 & 33.61 & 34.11 & 35.20 \\
\hline $\mathrm{C} 19$ & 11.67 & 10.50 & 11.29 & 11.38 & 13.15 & 11.78 \\
\hline C20 & 16.82 & 16.63 & 17.06 & 17.54 & 19.58 & 21.58 \\
\hline C21 & 43.67 & 42.16 & 45.67 & 45.67 & 46.88 & 49.95 \\
\hline C22 & 24.52 & 19.70 & 20.78 & 21.09 & 23.27 & 21.78 \\
\hline C23 & 9.39 & 8.20 & 8.33 & 8.38 & 8.26 & 8.78 \\
\hline
\end{tabular}

ant colony algorithm correction model, the calculation results show that $C=0.060, p=1.00$, and it shows that the prediction accuracy for main girder deformation of this paper's model is in excellent range and superior to that of the other two prediction models.

To sum up, the proposed model can achieve fast computation and high prediction accuracy using a few measured data through easy programming and simple operation. The case study reveals that the model is an excellent tool for predicting SCS-enhanced main girder deformation in the tensioning phase, shedding new light on main girder deformation control and prediction.

In the same way, the deformation values of the next tensioning phase $(1,995 \mathrm{kN})$ are extrapolated. Table 8 contains the prediction values obtained by FEM, UIGM $(1,1)$, OCUIGM (1,1), MC-UIGM (1,1), ACA model, and ACAC model. The results show that the forecast values of first five models are generally low. The C3 deformation values obtained by ACAC model are largest when the cable tension is drawn to $95 \%$ design tension value, and its value is $55.27 \mathrm{~mm}$.

\section{Conclusion}

It is difficult to accurately predict the girder deformation of PSC continuous box girder bridges enhanced by the SCS, owing to the complex deformation mechanism. The existing prediction models, lacking the modelling based on measured data, face low accuracy and poor adaptability in application. To overcome these defects, this paper combines the ant colony algorithm and the combined residual correction model into a new prediction model, which not only tackles the complexity, nonlinearity, uncertainty, and high cost, but also mines out the inherent deformation rules of main girder under the tensioning force. The new model was compared 
with finite element model, $\operatorname{UIGM}(1,1)$, one-time residual correction UIGM (1,1), Markov chain residual correction $\operatorname{UIGM}(1,1)$, and ant colony algorithm model. The main conclusions are as follows.

(1) Compared with the unequal interval GM (1,1), onetime residual correction UIGM (1,1), and Markov chain residual correction UIGM $(1,1)$, ant colony algorithm prediction model takes into account the time-space effect of deformation development of multiple points, and it can better dig out the inherent rules of the original data and make the prediction results more accurate, and its mean absolute error is $5.90 \%$.

(2) Using residual combination correction model to modify the predicted result of the ant colony algorithm can well simulate the trend components and random fluctuation compositions of the main girder deformation, and it has high prediction accuracy and the mean absolute error of perdition values is $3.39 \%$, the posterior error ratio is 0.060 , and the accuracy level reaches level 1 . The prediction precision is improved greatly; the paper's model has a certain theoretical and engineering application value.

(3) The model needs less measured data, the principle of the model is simple, and it is easy for programming, but the theory of optimal parameter selection needs to be further improved in the follow-up work so as to improve its forecasting efficiency and expand the range of adaptation. Unlike the finite element model, the model must be modelled based on three continuous and of equal interval measured data.

\section{Data Availability}

The data used to support the findings of this study are available from the corresponding author upon request.

\section{Conflicts of Interest}

The authors declare that there are no conflicts of interest regarding the publication of the paper.

\section{Acknowledgments}

This work presented herein has been supported by the National Natural Science Foundation of China (No. 11372165) and Project of Science and Technology of Western Region Transportation Construction, Ministry of Transport (No. 2011318223940).

\section{References}

[1] S. Asamoto, K. Kato, and T. Maki, "Effect of creep induction at an early age on subsequent prestress loss and structural response of prestressed concrete beam," Construction and Building Materials, vol. 70, pp. 158-164, 2014.

[2] N. Bagge, J. Nilimaa, and L. Elfgren, "In-situ methods to determine residual prestress forces in concrete bridges," Engineering Structures, vol. 135, pp. 41-52, 2017.

[3] G. N. Xu, Y. Z. Wang, S. M. Wang, and L. Y. Wang, "Key construction techniques for strengthening of main girder of
Dongming Huanghe River Highway Bridge," Bridge Construction, vol. 47, no. 5, pp. 101-106, 2017.

[4] Z. P. Bažant, Q. Yu, and G.-H. Li, "Excessive long-time deflections of prestressed box girders. I: record-span Bridge in Palau and other paradigms," Journal of Structural Engineering, vol. 138, no. 6, pp. 687-696, 2012.

[5] B. El-Ariss, "Stiffness of reinforced concrete beams with external tendons," Engineering Structures, vol. 26, no. 14, pp. 2047-2051, 2004.

[6] M. Qapo, S. Dirar, J. Yang, and M. Z. E. B. Elshafie, "Nonlinear finite element modelling and parametric study of CFRP shearstrengthened prestressed concrete girders," Construction and Building Materials, vol. 76, pp. 245-255, 2015.

[7] T. Guo, Z. Chen, T. Liu, and D. Han, “Time-dependent reliability of strengthened PSC box-girder bridge using phased and incremental static analyses," Engineering Structures, vol. 117, pp. 358-371, 2016.

[8] Z. P. Bažant, Q. Yu, and G.-H. Li, "Excessive long-time deflections of prestressed box girders. I: record-span Bridge in Palau and other paradigms," Journal of Structural Engineering, vol. 138, no. 6, pp. 676-686, 2012.

[9] A. Bezuglov and G. Comert, "Short-term freeway traffic parameter prediction: Application of grey system theory models," Expert Systems with Applications, vol. 62, pp. 284-292, 2016.

[10] Q. Zhou and V. V. Thai, "Fuzzy and grey theories in failure mode and effect analysis for tanker equipment failure prediction," Safety Science, vol. 83, pp. 74-79, 2016.

[11] J. Yu, X. Zhang, and C. Xiong, "A methodology for evaluating micro-surfacing treatment on asphalt pavement based on grey system models and grey rational degree theory," Construction and Building Materials, vol. 150, pp. 214-226, 2017.

[12] F. Chen, L. Liu, and T. Huang, "Study on settlement prediction of metro tunnels ant colony algorithm," Tunnel Construction, vol. 33, no. 6, pp. 462-468, 2013.

[13] M. J. Blondin, J. Sanchis, P. Sicard, and J. M. Herrero, "New optimal controller tuning method for an AVR system using a simplified Ant Colony Optimization with a new constrained Nelder-Mead algorithm," Applied Soft Computing, vol. 62, pp. 216-229, 2018.

[14] B. C. Mohan and R. Baskaran, "A survey: ant colony optimization based recent research and implementation on several engineering domain," Expert Systems with Applications, vol. 39, no. 4, pp. 4618-4627, 2012.

[15] A. Colorni, M. Dorigo, and V. Maniezzo, "Distributed optimization by ant colonies," in Proceedings of the ECAL91 European Conference on Artificial Life, pp. 134-142, Elsevier, Paris, France, 1991.

[16] H. B. Duan and D. B. Wang, "Research and improvement on the global convergence of ant colony algorithm," Systems Engineering and Electronics, vol. 26, no. 10, pp. 1506-1509, 2004.

[17] H. B. Duan, D. B. Wang, J. Q. Zhu, and X. H. Huang, "Development on ant colony algorithm theory and its application," Control and Decision, vol. 19, no. 12, pp. 1321-1326, 2004.

[18] K. Wei, Q.-M. Gong, and S.-H. Zhou, "Forecast of longterm settlement of metro tunnel on the basis of ant colony optimization," Tiedao Xuebao/Journal of the China Railway Society, vol. 30, no. 4, pp. 79-83, 2008.

[19] K. Wei, Q. Gong, and S. Zhou, "Ant colony algorithms of longterm uneven settlement prediction in tunnel," Tongji Daxue Xuebao/Journal of Tongji University, vol. 37, no. 8, pp. 993-998, 2009. 
[20] Y. Guo and J. M. Gao, “Track irregularity evolution prediction for high speed railways in frozen ground region based on GM(1, 1) power model," Journal of Railway Science and Engineering, vol. 13, no. 5, pp. 791-799, 2016.

[21] Y. Huang and W. Fang, "Power load forecasting model with residual error correction based on gray Fourier transform," Dianli Zidonghua Shebei/Electric Power Automation Equipment, vol. 33, no. 9, pp. 105-112, 2013.

[22] G. Xu, Y. Wang, S. Wang, and Q. Yuan, "Deformation Forecast of Main Girder Enhanced by Stay Cable System with Unequal Interval Grey Model and Residual Composite Correction," Mathematical Problems in Engineering, vol. 2018, Article ID 6373086, 11 pages, 2018.

[23] K. G. Li, J. Xu, and G. Y. Huang, "Prediction for slope displacment based on unequal interval GM $(1,1)$ model," Chinese Journal of Underground Space and Engineering, vol. 2, no. 6, pp. 998-992, 2006.

[24] Y. H. Huang, J. C. Peng, C. C. Li, D. Liu, and G. Q. Sun, "Application of Markov theory in mid-long term load Forecasting," in Proceedings of the Y. - H. Huang, vol. 23, pp. 131-136, 2011.

[25] J. L. Deng, Basic Theory of Grey System, Huazhong University of Science and Technology Press, Wuhan, China, 2002.

[26] H. Sousa, J. Bento, and J. Figueiras, "Construction assessment and long-term prediction of prestressed concrete bridges based on monitoring data," Engineering Structures, vol. 52, pp. 26-37, 2013.

[27] Z. Lü and Z. Pan, "Issues in design of long-span prestressed concrete box girder bridges," Tumu Gongcheng Xuebao/China Civil Engineering Journal, vol. 43, no. 1, pp. 70-76, 2009.

[28] K. Q. Zheng, Z. Liu, Y. F. Zhang, and S. Q. Qin, "Shear stiffness assessment method for concrete girder bridges with web diagonal cracks," Bridge Construction, vol. 45, no. 4, pp. 4651, 2015.

[29] JTG/T H21-2011, Standards for technical condition evaluation of highway bridges, China Communications Press, Beijing, China, 2011.

[30] Research Institute of Highway Ministry of Transport, Report of testing and evaluation of Dongming Huanghe River Highway Bridge in Shandong, Beijing, China, 2013.

[31] X. S. Zhang, M. X. Zao, and X. W. Wang, "Application of modified empennage residual error $\operatorname{GM}(1,1)$ model in prediction of pipeline corrosion," China Safety Science Journal, vol. 27, no. 1, pp. 65-70, 2017. 


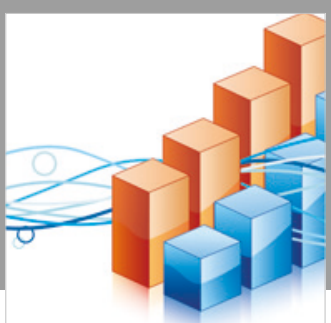

Advances in

Operations Research

\section{-n-m}
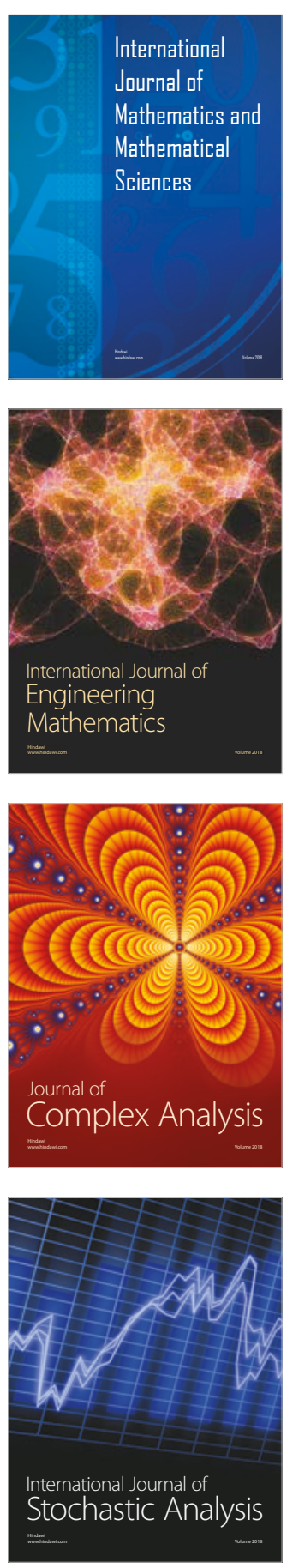
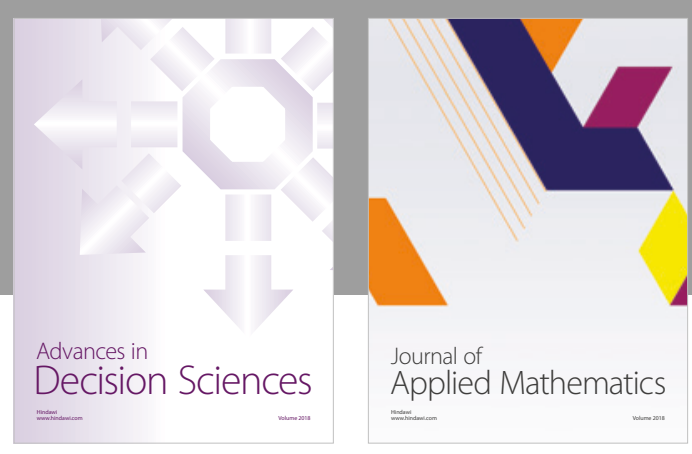

Journal of

Applied Mathematics
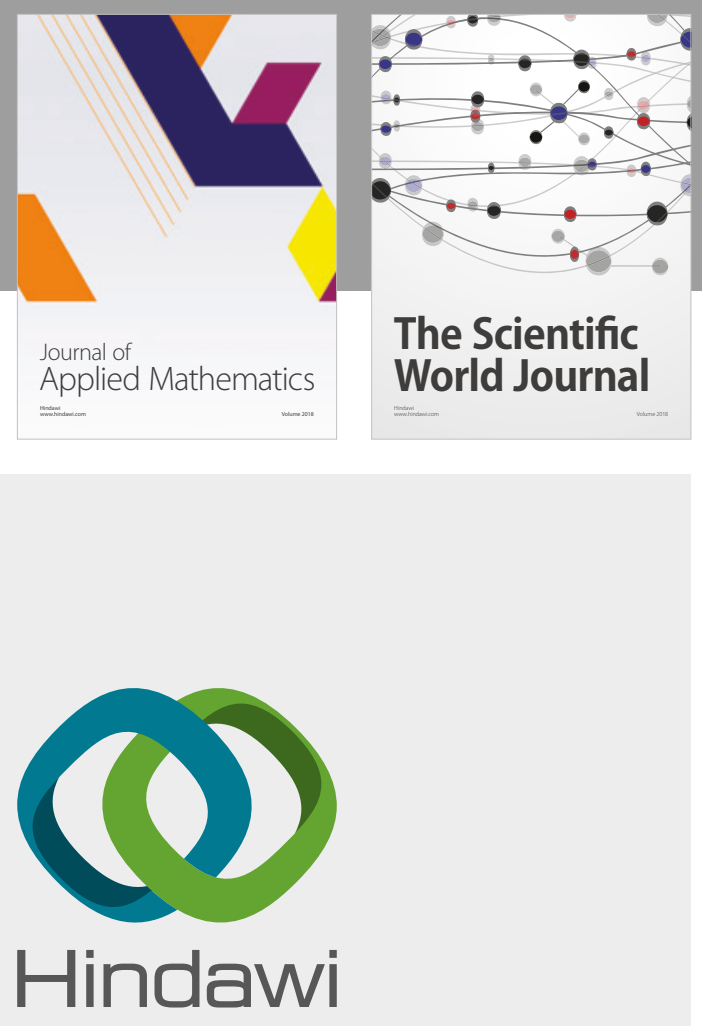

Submit your manuscripts at

www.hindawi.com

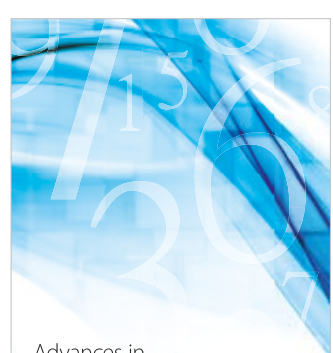

Advances in
Numerical Analysis
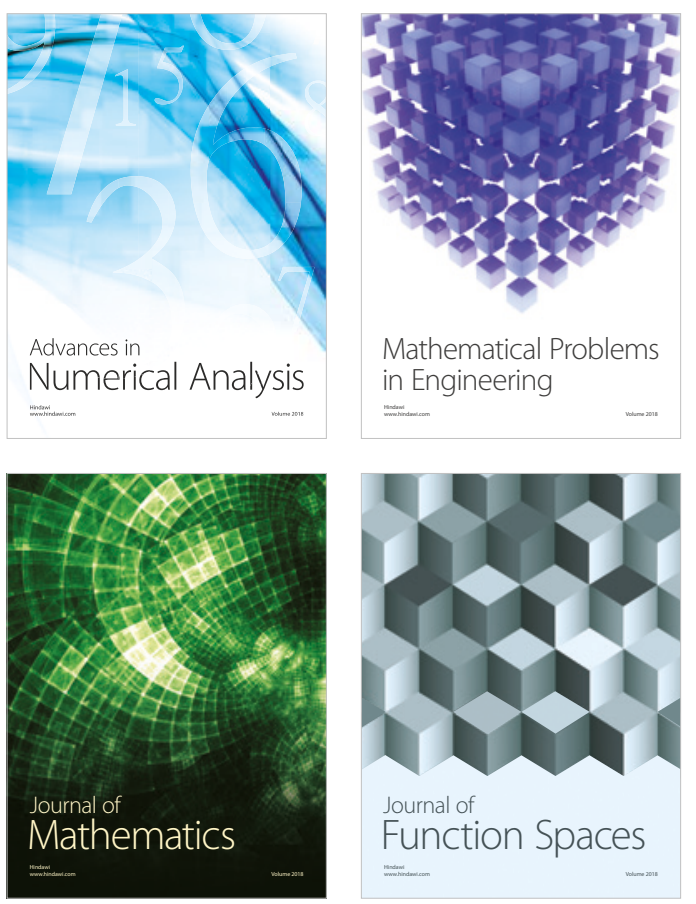

Mathematical Problems in Engineering

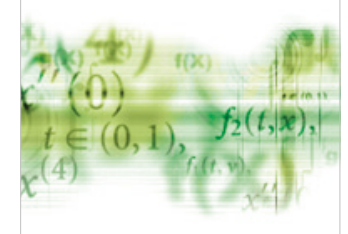

International Journal of

Differential Equations

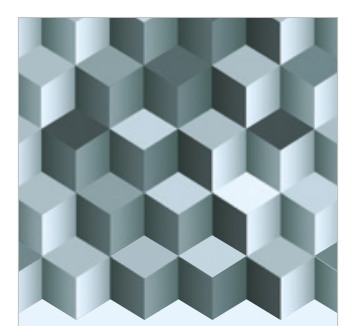

Journal of

Function Spaces

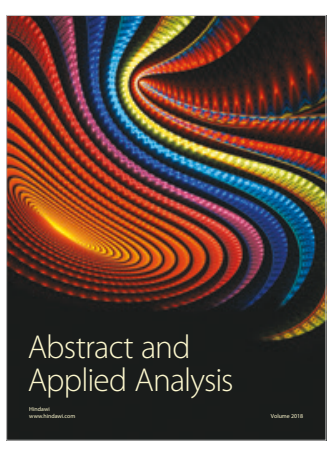

The Scientific

World Journal

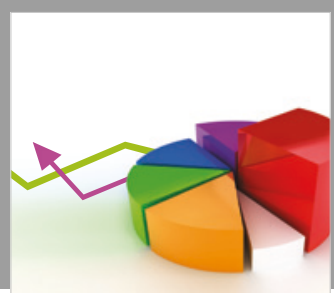

Journal of

Probability and Statistics
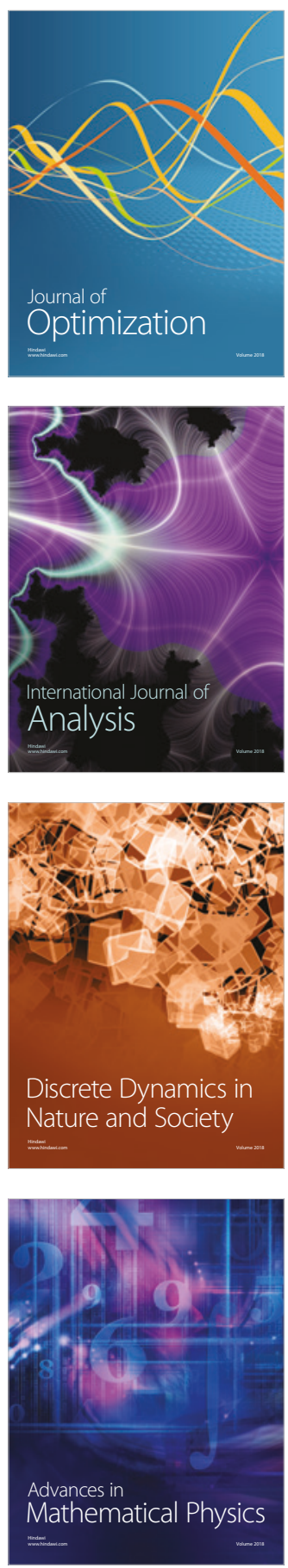